\title{
RECENT CHANGES IN INFECTIOUS DISEASES IN EUROPEAN WILDLIFE
}

\author{
Lisa Yon, ${ }^{1,16,17}$ d, Paul Duff, ${ }^{2,16}$ Erik O. Ågren, ${ }^{3}$ Károly Erdélyi, ${ }^{4}$ Ezio Ferroglio, ${ }^{5}$ Jacques \\ Godfroid, ${ }^{6}$ Jean Hars, ${ }^{7}$ Gete Hestvik, ${ }^{3}$ Dan Horton, ${ }^{8}$ Thijs Kuiken, ${ }^{9}$ Antonio Lavazza, ${ }^{10}$ Iwona \\ Markowska-Daniel,,${ }^{11}$ An Martel, ${ }^{12}$ Aleksija Neimanis, ${ }^{3}$ Frank Pasmans, ${ }^{12}$ Stephen Price, ${ }^{13}$ \\ Francisco Ruiz-Fons, ${ }^{14}$ Marie-Pierre Ryser-Degiorgis, ${ }^{15}$ Frederik Widén, ${ }^{3}$ and Dolores Gavier- \\ Widén ${ }^{3,16}$ \\ ${ }^{1}$ School of Veterinary Medicine and Science, Faculty of Medical and Health Sciences, The University of Nottingham, \\ Sutton Bonington, Leicestershire LE12 5RD, UK, Orcid ID\#0000-0002-9765-3192 \\ ${ }^{2}$ Animal and Plant Health Agency Diseases of Wildlife Scheme, (APHA DoWS), Penrith, Cumbria CA11 9RR, UK \\ ${ }^{3}$ National Veterinary Institute (SVA), SE75189 Uppsala, Sweden \\ ${ }^{4}$ Veterinary Diagnostic Directorate - National Food Chain Safety Office, Tabornok u.2, 1143, Budapest, Hungary \\ ${ }^{5}$ University of Turin, Largo Paolo Braccini, 2 (già Via L. DaVinci, 44)- 10095 Grugliasco (TO), Torino, Italy \\ ${ }^{6}$ University of Troms $\varnothing$ - the Arctic University of Norway, Postbox 6050 Langnes, 9037 Troms $ø$, Norway \\ ${ }^{7}$ Office National de la Chasse et de la Faune Sauvage (ONCFS), 5 all Bethleem, 38610 Gieres, France \\ ${ }^{8}$ University of Surrey, GU2 7XH, Guildford, UK \\ ${ }^{9}$ Erasmus University Medical Centre, Wytemaweg 80, 3015 CN Rotterdam, The Netherlands \\ ${ }^{10}$ Istituto Zooprofilattico Sperimentale della Lombardia e dell'Emilia Romagna (I.Z.S.L.E.R.), Via Antonio Bianchi 7/9, \\ 25124 Brescia, Italy \\ 11 Warsaw University of Life Sciences, ul. 159c Noworsynowska Str., 02776 Warsaw, Poland \\ 12 Department of Pathology, Bacteriology and Avian Diseases, Faculty of Veterinary Medicine, Ghent University. \\ Salisburylaz 133 9820 Morolboke Bolgium \\ ${ }^{13}$ UCL Genetics Institute, Gower Street, London WC1E 6BT, UK \\ ${ }^{14}$ Spanish Wildlife Research Institute IREC, Ronda de Toledo s/n 13005, Ciudad Real, Spain \\ Z- Eentre for Fish and Wildlife Health, Vetsuisse Faculty, University of Bern, Langgass-str. 122, 3001 Bern, Switzerland \\ $\square \equiv$ These authors served as principal editors of this manuscript \\ Corresponding author (email: lisa.yon@nottingham.ac.uk)
}

?1 ?2 ABSTRACT: Many infectious diseases originating from, or carried by, wildlife affect wildlife conservation and biodiversity, livestock health, or human health. We provide an update on changes in the epidemiology of 25 selected infectious, wildlife-related diseases in Europe (from 2010-16) that had an impact, or may have a future impact, on the health of wildlife, livestock, and humans. These pathogens were selected based on their: 1) identification in recent Europe-wide projects as important surveillance targets, 2) inclusion in European Union legislation as pathogens requiring obligatory surveillance, 3) presence in recent literature on wildlife-related diseases in Europe since 2010, 4) inclusion in key pathogen lists released by the Office International des Epizooties, 5) identification in conference presentations and informal discussions on a group email list by a European network of wildlife disease scientists from the European Wildlife Disease Association, or 6) identification as pathogens with changes in their epidemiology during 2010-16. The wildlife pathogens or diseases included in this review are: avian influenza virus, seal influenza virus, lagoviruses, rabies virus, bat lyssaviruses, filoviruses, canine distemper virus, morbilliviruses in aquatic mammals, bluetongue virus, West Nile virus, hantaviruses, Schmallenberg virus, Crimean-Congo hemorrhagic fever (CCHF) virus, African swine fever virus, amphibian ranavirus, hepatitis E virus, bovine tuberculosis (Mycobacterium bovis), tularemia (Francisella tularensis), brucellosis (Brucella spp.), salmonellosis (Salmonella spp.), Coxiella burnetii, chytridiomycosis, Echinococcus multilocularis, Leishmania infantum, and chronic wasting disease. Further work is needed to identify all of the key drivers of disease change and emergence, as they appear to be influencing the incidence and spread of these pathogens in Europe. We present a summary of these recent changes during 2010-16 to discuss possible commonalities and drivers of disease change and to identify directions for future work on wildlife-related diseases in Europe. Many of the pathogens are entering Europe from other continents while others are expanding their ranges inside and beyond Europe. Surveillance for these wildlife-related diseases at a continental scale is therefore important for planet-wide assessment, awareness of, and preparedness for the risks they may pose to wildlife, domestic animal, and human health.

Keywords: Emerging disease, epidemiology, Europe, human health, livestock health, pathogen, wildlife health. 


\section{INTRODUCTION}

In recent decades, there has been increasing recognition of infectious diseases originating from, or carried by, wildlife. Most emerging infectious diseases (EIDs) exist "within a host and parasite continuum between wildlife, domestic animal, and human populations" (Daszak et al. 2000), and pathogen transmission across interfaces between the three is frequently complex. Emerging infectious disease events are predominantly zoonoses (60.3\% of EIDs); the majority of these $(71.8 \%)$ originate from wildlife (Jones et al. 2008). Wildlife species can play a role in the epidemiology of pathogens that can affect domestic animal and human health by serving as reservoir hosts. However, there are also many pathogens, regardless of origin, causing diseases that pose a significant threat to endangered wildlife species and, ultimately, to the conservation of biodiversity (Woolhouse 2002). Among these are distemper in the Amur tiger (Panthera tigris altaica; Gilbert et al. 2014), chytridiomycosis in frogs (Skerratt et al. 2007), and squirrelpox in red squirrels (Sciurus vulgaris; Thomas et al. 2003).

Several risk factors are believed to have contributed to the worldwide increase of EIDs in the last five decades (Jones et al. 2008). Drivers associated with globalization (including travel, trade, and tourism) and influence from features of the natural environment (including environmental change and climate change) were found to be significant factors associated with infectious disease threat events in Europe between 2008 and 2013 (Semenza et al. 2016). Furthermore, there have been environmental changes that alter, usually with an increasing trend, the distribution and number of wild hosts and the numbers of potential pathogen vector species in Europe. These also facilitate pathogen transmission, as observed for example by the changes in the epidemiology of West Nile virus (WNV) infection and leishmaniasis (Semenza and Menne 2009) due to the enlarged geographic ranges of their vector hosts.
Europe is characterized by high humanpopulation densities over most of the continent, a history of extensive, polluting, heavy industries, and intensive agriculture with high livestock populations, and only a few temperate areas remain unchanged by humans. As a result, wildlife in Europe has seemingly been pushed to the periphery in many cases. In other cases, however, wildlife has had time to adapt to the altered environment.

The epidemiology of infections in wildlife in Europe can differ from that of similar wildlife infections elsewhere in the world. For example, the two subspecies of Francisella tularensis important for disease in humans and animals are $F$. tularensis subsp. tularensis (type A) and F. tularensis subsp. holarctica (type B). Type A is found solely in North America while Type B is predominantly in Asia and Europe (Hestvik et al. 2015). Similarly, there are many species of hantaviruses, with markedly different epidemiology and clinical presentations, which have been identified in different geographic regions including Asia, the Americas, and Europe (Jonsson et al. 2010). Bat lyssaviruses likewise have very different host populations and transmission dynamics in Europe (Fooks et al. 2003; Johnson et al. 2010) than in the Americas (Kuzmin et al. 2012). There are also clear regional differences in pathogens or in species susceptibility to pathogens. This has been seen in the absence of mass mortality from white nose syndrome in European bat populations, in contrast to frequent mass mortalities in North America (Puechmaille et al. 2011). Thus, to understand wildlife disease epidemiology in Europe, it is essential to gather region-specific pathogen data.

Wildlife disease surveillance is essential to identify changes in wildlife disease occurrence and epidemiology and is considered an integral part of a One-Health approach (http://www. onehealthinitiative.com/), particularly where it links with human and livestock health surveillance. Surveillance is needed to identify new and re-emerging pathogens, to identify possible changes in host species and, in vector ranges ${ }_{A}$ to plan appropriate responses. In Europe there is significant interest in wildlife health surveil- 
lance: more than 18,000 wild animals are investigated in the framework of general (passive) surveillance programs (by postmortem examination and sampling) and more than 50,000 in targeted (active) surveillance programs annually, and both are deemed necessary for detection of current and emerging pathogens. Furthermore, wildlife scientists involved in these investigations have set up an active network to facilitate the rapid exchange of information on EID events (Kuiken et al. 2011). General wildlife disease surveillance is important for the early detection of new diseases. For example, the first cases of African swine fever (ASF) in the four European Union (EU) countries affected to date (Poland, Lithuania, Latvia, and Estonia) were detected by testing wild boars that were found dead (Gavier-Widén et al. 2015). Targeted surveillance of certain wildlife diseases (e.g., rabies, avian influenza, ASF, and classical swine fever $[\mathrm{CSF}])$ are compulsory at the EU level. Such wildlife disease surveillance information is essential to inform risk assessments for pathogens that pose a threat to animal and human populations, improve regional preparedness, estimate the impact of these pathogens on animal and human populations, and identify areas that should be prioritized for funding (Semenza et al. 2016).

We used data from wildlife health surveillance in European countries to provide an update on changes in the epidemiology of selected infectious diseases in European wildlife. Each of these pathogens was selected because some or all of the following criteria applied:

1) They were identified as important surveillance targets in one or more recent Europe-wide projects involving wildlife disease surveillance (WildTech, ASF-STOP, EMIDA-APHAEA ANIHWA-ECALEP [Emergence of highly pathogenic CAliciviruses in LEporidae], MedVetNet [see definitions in Table 1]) in which many of the authors have been involved.

2) They were identified by the EU and legislated for obligatory surveillance and control by all the Member States (European Commission 2017).

3) They were identified in recent (since 2010) literature on wildlife-related disease in Europe. For example, eight diseases caused by pathogens included here were also identified by Ciliberti et al. (2015) from an expert risk analysis review of wildlife pathogens in Europe to be prioritized for surveillance-rabies, bovine tuberculosis, brucellosis, bluetongue, Q fever, salmonellosis, CCHF, and transmissible spongiform encephalopathies.

4) Of the 25 selected diseases, 21 are listed by the Office International des Epizooties (OIE). This organization, also known as the World Organisation of Animal Health, lists the most significant animal diseases globally and has two series relevant to wildlife. The first series is the OIE-Listed Diseases of Livestock and Wildlife Globally (OIE 2018; Q fever, bovine tuberculosis, rabbit hemorrhagic disease [RHD], highly pathogenic avian influenza, bluetongue, brucellosis, Crimean-Congo hemorrhagic fever, echinococcosis, rabies, tularemia, West Nile fever, African swine fever [ASF], chytridiomycosis, and amphibian ranavirus disease). The second series is the OIE-Listed Diseases Affecting Wildlife (OIE 2013; chronic wasting disease [CWD], European brown hare syndrome [EBHS], and the diseases caused by filoviruses, hantaviruses, marine mammal morbilliviruses, Salmonella enterica serovars, and Batrachochytrium salamandrivorans).

5) The pathogens were repeatedly identified by a European network of wildlife disease scientists from the European Wildlife Disease Association (EWDA) - through formal presentations at meetings and informal discussions on their group email list (EWDA 2016) —as having an important impact on human and animal populations.

6) There were published reports of changes in the epidemiology of the pathogen during the period of the review (2010- 
TABLE 1. European Union (EU) wildlife disease programs and their priority diseases/pathogens.

\begin{tabular}{|c|c|c|}
\hline EU program name & Year/final report & Diseases/pathogens included in program \\
\hline WILDTECH $^{\mathrm{a}}$ & 2015 & $\begin{array}{l}\text { Mycobacterium bovis, Brucella spp., Salmonella spp., } \\
\text { Echinococcus multilocuralis, avian influenza virus (HP), } \\
\text { rabies virus, Francisella tularensis, Coxiella burnetii (Q fever), } \\
\text { Batrachochytrium spp. (chytridiomycosis), bluetongue virus, } \\
\text { West Nile virus, hepatitis E virus, Orthohantavirus spp., } \\
\text { European brown hare syndrome virus }\end{array}$ \\
\hline ASF-STOP $^{b}$ & Ongoing 2018 & African swine fever virus \\
\hline EMIDA-APHAEA-ANIHWA ${ }^{\mathrm{C}}$ & Ongoing 2018 & Echinococcus multilocularis, Francisella tularensis \\
\hline MedVetNet WiREDZ SIG ${ }^{\mathrm{d}}$ & 2009 & Rabies, Orthohantavirus spp., tularemia \\
\hline
\end{tabular}

${ }^{a}$ Novel technologies for surveillance of emerging and re-emerging infections of wildlife (European Commission 2015).

${ }^{\mathrm{b}}$ Understanding and combating African Swine Fever in Europe (ASF-STOP COST Action 2016).

${ }^{\mathrm{c}}$ Harmonized approaches in monitoring wildlife population health and ecology and abundance (APHAEA 201\$)

${ }^{\mathrm{d}}$ Special Interest Group (SIG) in wildlife-related emerging diseases and zoonoses (WiREDZ). Med-Vet-Net 2008; Medical-VeterinaryNetwork-A Network of Excellence for Zoonoses research funded by the European Union.

16) such as for ASF, CWD, and RHD. We have cited this literature below.

We do not suggest that these are the most important diseases in wildlife in Europe or that those selected represent an exhaustive list. While these categories are not mutually exclusive, and many pathogens may have impacts across multiple categories, we have grouped these based on their predominant impacts (see also Table 2).

By definition, surveillance means collecting information for the purpose of taking action, and it requires not only data collection but also data analysis and communication (Ryser-Degiorgis 2013). Herein, we have compiled information from wildlife disease surveillance activities at a continental scale. This information can serve as a resource for researchers, policy makers, public health professionals, and animal health scientists with which to better understand current and emerging infectious disease risks, to inform policy, planning, and preparedness, and to integrate these activities with corresponding initiatives in human and livestock health.

\section{WILDLIFE PATHOGENS WITH PRIMARY IMPACTS ON PUBLIC HEALTH}

\section{Bat lyssavirus infections, by Dan Horton}

All 16 classified Lyssavirus species can cause rabies, and there is good evidence that bats are reservoir hosts for the majority of them (Badrane and Tordo 2001; Fooks et al. 2014). Documented spillover into humans and domestic animals in Europe demonstrates a low but real public health risk. Until recently, three Lyssavirus species had been reported in European bats (Table 3). The majority of bat rabies cases reported in Europe (average of 34 cases per year 2000-14) are due to European bat lyssavirus type 1 (EBLV-1) in Serotine bats (Eptesicus serotinus, Eptesicus isabellinus; Schatz et al. 2013). Fewer than 30 cases of European bat lyssavirus type 2 (EBLV-2) infection have been reported, with more restricted distribution in the UK and Northern Europe in Myotis daubentonii and Myotis dasycneme (McElhinney et al. 2013). In addition, one detection of the antigenically divergent West Caucasian bat lyssavirus was reported in 2002 in a Miniopterus schreibersii from the Caucasus region of Russia (Botvinkin et al. 2003; Kuzmin et al. 2006).

Since 2010, two additional lyssaviruses have been detected in Europe. Bokeloh bat lyssavirus was detected in Germany in 2010 in a Natterer's bat (Myotis nattereri) and has subsequently been detected twice in $M$. nattereri in eastern France, and Germany, both in 2012 (Nolden et al. 2014). Also in 2012, genetic evidence for another putative European lyssavirus, Lleida bat lyssavirus, was detected in brain tissue from a sick 
Miniopterus schreibersii in Spain (Arechiga Ceballos et al. 2013). Although lack of viable virus has precluded antigenic assessment of this new virus, genetic analysis suggests it is most closely related to an African virus, Ikoma lyssavirus, against which current vaccines are considered unlikely to confer protection (Horton et al. 2014).

Spillover of European bat lyssaviruses into other hosts is rare, but occurs. There have been at least four reported cases of human rabies caused by bat lyssaviruses in Europe (EBLV-1 and EBLV-2) in addition to isolated reports of rabies in domestic animals and wildlife caused by EBLV-1 (Johnson et al. 2010; Schatz et al. 2013). There has been no documented evidence for further transmission of EBLV-1 between individuals in a non-bat host population. In contrast, Rabies lyssavirus in the Americas has repeatedly been transmitted from bats into carnivores and then continued to be transmitted between individuals of the carnivore spillover host (Kuzmin et al. 2012). Considerable interest has therefore been directed at understanding viral dynamics in bat reservoirs to assess risk of spillover into other species, but many questions remain. Experimental infections showed no evidence for viral persistence or subclinical infection in bats, yet serologic surveys demonstrate antibodies in a high proportion of apparently healthy bats (Johnson et al. 2008; Freuling et al. 2009), suggesting infection dynamics may differ between bats and carnivores. Longitudinal surveillance and disease dynamics models are improving our understanding of how lyssaviruses are maintained (Schatz et al. 2013). A crucial consideration in public education about bats, and in planning surveillance programs, is that all bat species are protected in Europe. Therefore, surveillance activities should involve close collaboration between conservationists, biologists, and public health professionals (Racey et al. 2013).

\section{Coxiella burnetii infection, by Francisco Ruiz-Fons}

$Q$ fever is a reproductive disease of ruminants caused by Coxiella burnetii, which displays one of the widest host ranges of known pathogenic bacteria. Coxiella burnetii can reproduce in many mammalian, avian, reptilian, and arthropod species. However, a definitive role for wildlife in the epidemiology of $\mathrm{Q}$ fever in livestock and humans has not been established.

The last decade witnessed one of the largest reported human $Q$ fever outbreaks. It occurred in The Netherlands and was linked to increases in farming of dairy goats (Capra aegagrus hircus; Roest et al. 2011), resulting in a very high density of farmed goats in a small region. However, other European countries have also reported annual cases, some of unknown origin. Whether wildlife may be implicated in transmission of C. burnetii to humans and livestock in Europe is poorly understood. In Europe, C. burnetii is present in wild and zoo ungulates, carnivores in zoologic collections, rodents, lagomorphs, and wild birds. However, reports are geographically scattered, and little extensive surveillance has been done to identify the role of any of these species in C. burnetii dynamics. Two recent studies on European rabbit (Oryctolagus cuniculus) and red deer (Cervus elaphus) populations in Spain and Portugal (González-Barrio et al. 2015) determined that $C$. burnetii can replicate in, and be shed by, both of these species. Coxiella burnetii circulates in northern England/southern Scotland at medium-to-high antibody prevalences in small mammals (bank vole, Myodes glareolus; field vole, Microtus agrestis; and wood mouse, Apodemus sylvaticus) and red foxes (Vulpes vulpes) (Meredith et al. 2015). Recently, Iberian ibex (Capra pyrenaica) from southern Spain were also determined to be susceptible to C. burnetii infection (Márquez et al. 2014).

We will likely see increasing evidence that wildlife species participate in the dynamics of C. burnetii infection in livestock and humans. However, this increase in evidence will not necessarily suggest an increase in geographic or host ranges; rather, it may simply be a consequence of increasing and more accurate detection and assessment of the role of wildlife in the spread and maintenance of this pathogen. Future research on C. burnetii 


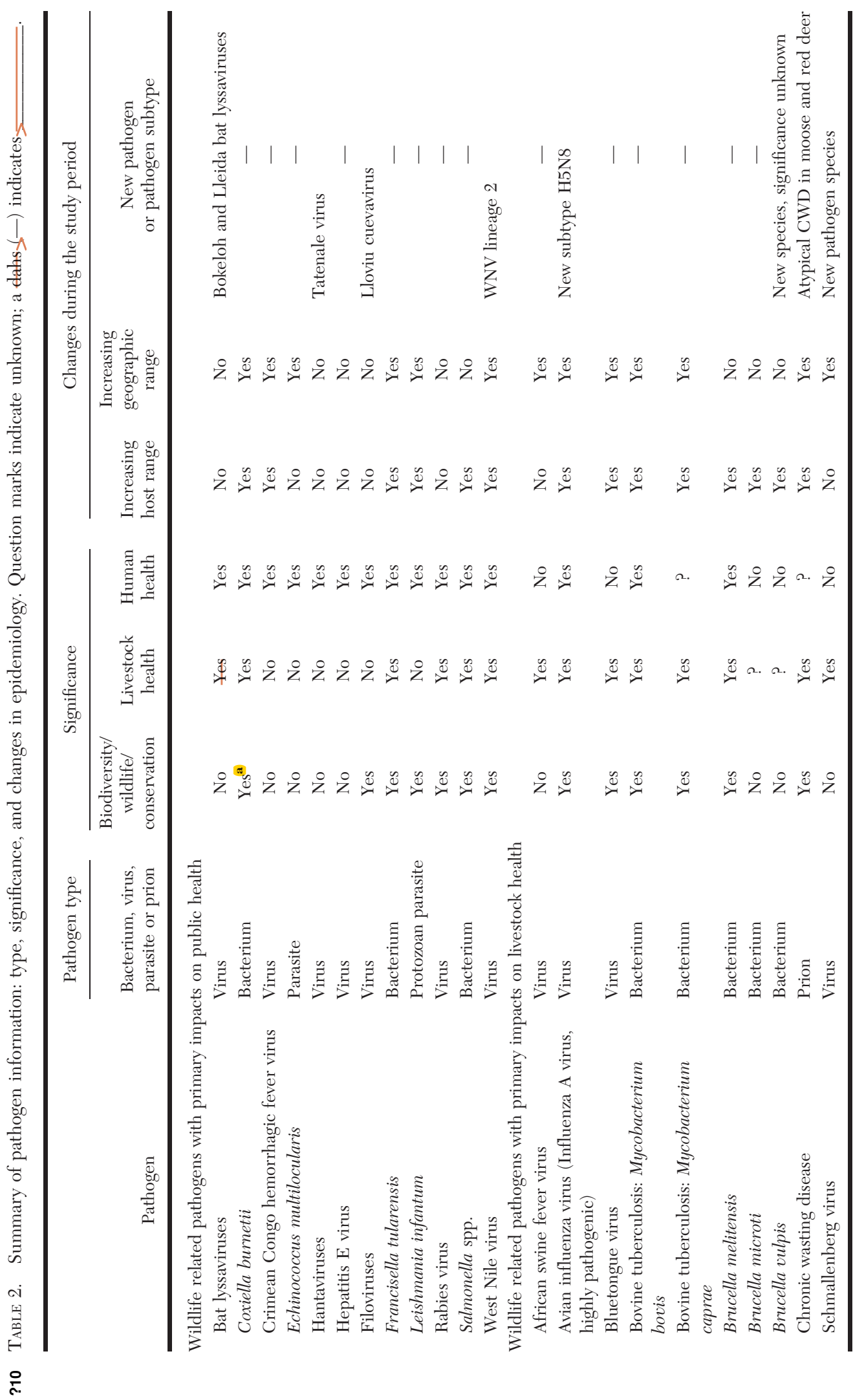


REVIEW 7

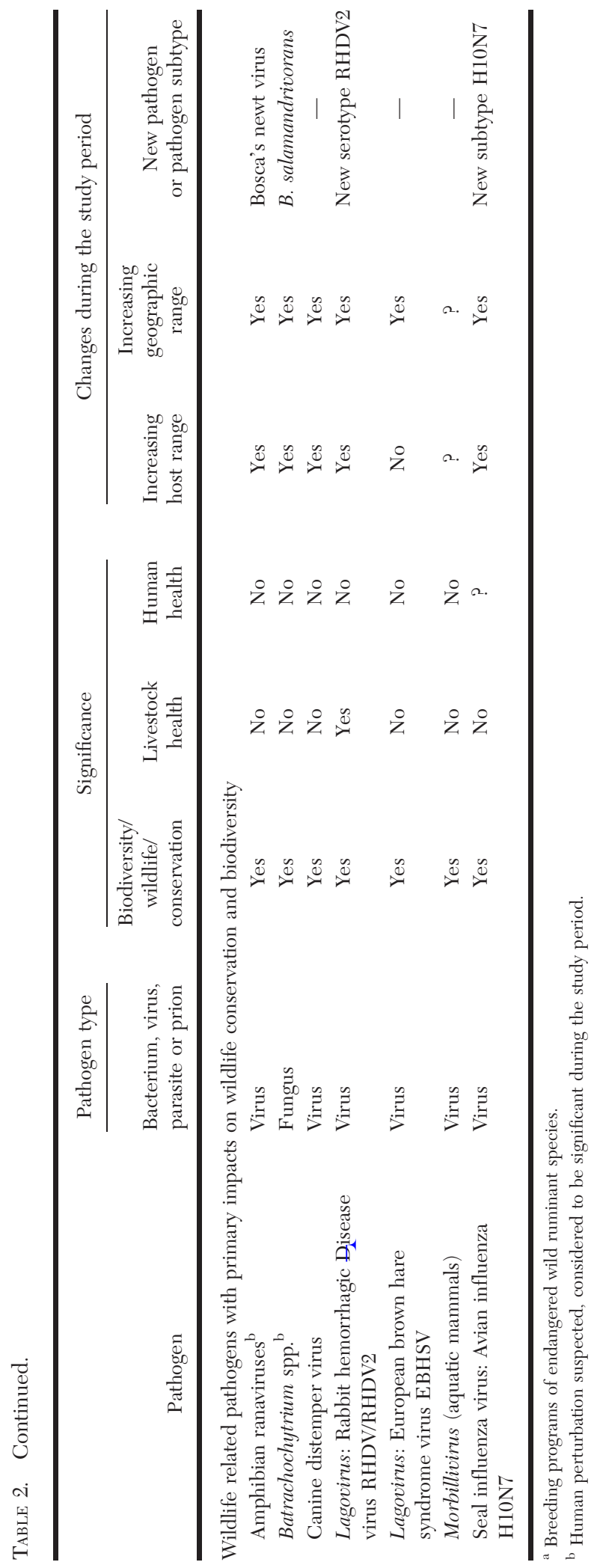


TABLE 3. Five bat lyssaviruses detected in Europe. ${ }^{\text {a }}$

\begin{tabular}{lll}
\hline \multicolumn{1}{c}{ Virus species } & Bat species most frequently associated & Geographic area detected \\
\hline European bat 1 lyssavirus & Eptesicus serotinus, Eptesicus isabellinus & Central and Southern Europe \\
European bat 2 lyssavirus & Myotis daubentonii, Myotis dasycneme & Northern Europe and UK \\
Bokeloh bat lyssavirus & Myotis nattereri & Central/Western Europe \\
West gaucasian bat virus & Miniopterus schreibersii & Eastern Europe (Russia) ${ }^{\mathrm{c}}$ \\
Lleida bat lyssavirus & Miniopterus schreibersii & Southern Europe (Spain) \\
\hline${ }^{\mathrm{a}}$ Data from Wise et al. (2017). & \\
${ }^{\mathrm{b}}$ Does not indicate absence in other areas. & \\
${ }^{\mathrm{c}}$ One isolation only. &
\end{tabular}

dynamics will likely underscore the complex epidemiology and subsequent difficulties in the control of $C$. burnetii infection in livestock and humans in Europe.

\section{Crimean-Congo hemorrhagic fever Orthonairovirus infections, by Francisco Ruiz-Fons}

Crimean-Congo hemorrhagic fever $(\mathrm{CCHF})$ is caused by a zoonotic, vector-borne Orthonairovirus in the family Nairoviridae. The hemorrhagic syndrome caused by Crimean-Congo hemorrhagic fever Orthonairovirus (CCHFV) affects only humans, and the disease is of concern as an emerging zoonotic threat on the European continent and in the Middle East (Mansfield et al. 2017).

Congo hemorrhagic fever Orthonairovirus circulates enzootically in a wild cycle involving several mammalian species and ticks; mainly, but not exclusively, ticks in the genus Hyalomma. Infection with CCHFV has been detected in a range of wildlife (hares [Lepus europaeus], hedgehogs [Erinaceus europaeus], other small mammals) and domestic animals (cattle [Bos taurus], goats [Capra hircus], sheep [Ovis aries], dogs [Canis lupus familiaris]; reviewed by Whitehouse [2004]). Many additional wildlife species have been found with antibody to CCHFV. However, although the pathogen was discovered in 1944 , there is no accurate information on the relationship between CCHFV and the most probable reservoir hosts in Europe (Spengler et al. 2016). Two scenarios are described in Europe, one in eastern Mediterranean countries and one (poorly understood) in the western Mediterranean (Estrada-Peña et al. 2012a). The CCHFV strains circulating in the eastern Mediterranean are public health concerns due to their high virulence. In western Mediterranean Europe, however, only CCHFV strains of African origin (and assumed to have low virulence) have been described (Estrada-Peña et al. 2012b). However, on 25 August 2016, a 62-yr-old man reporting a recent tick bite in central Spain died of CCHF (ProMED-Mail 2016). A nurse infected with CCHFV while caring for the patient recovered.

Wildlife may play several roles by serving as a host in which CCHFV replicates, serving as a source of infection for ticks, and by supporting replicating tick populations. Changes in wildlife population dynamics modulate tick population dynamics at local and regional scales, so they are considered important drivers of CCHFV infection prevalence in ticks (Estrada-Peña et al. 2012a). Wildlife community assemblages favoring circulation of CCHFV should therefore be identified for accurate mapping of risk factors (Estrada-Peña et al. 2013) and to predict future trends in CCHF in Europe to inform the development of a preventive strategy. There is an urgent need to involve wildlife disease researchers, wildlife ecologists, entomologists, and epidemiologists to address the many unanswered questions on CCHFV dynamics.

\section{Echinococcus multilocularis parasitism, by Erik Ågren}

Echinococcosis, or hydatid disease, is caused by infection with Echinococcus multi- 


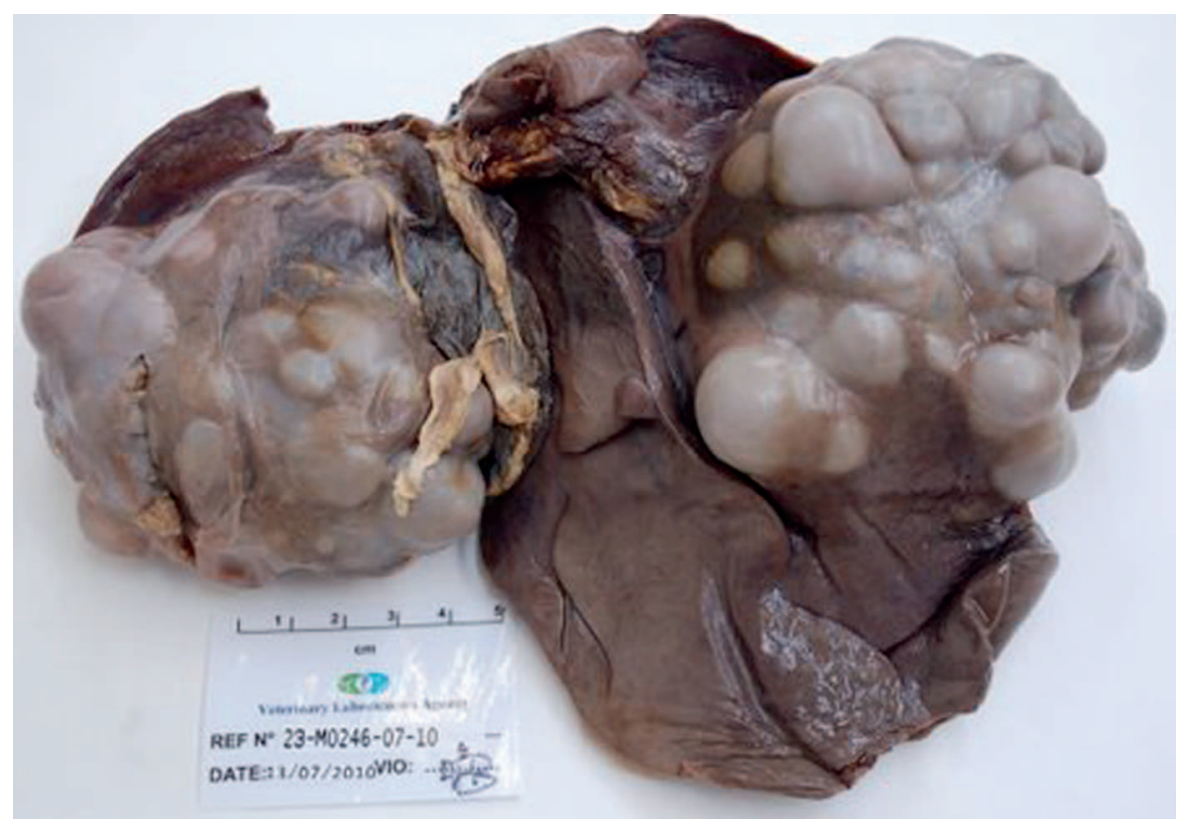

Figure 1. Fixed liver from a beaver (Castor fiber) with Echinococcus multilocularis (confirmed by laboratory testing) in July 2010, with parasitic cysts clearly visible; Animal Plant and Health Agency, Langford Veterinary Investigation Centre, Langford, Somerset, England. The first and only case of this pathogen to have occurred in Britain. (Photograph courtesy of Alex Barlow, Animal Plant and Health Agency, Diseases of Wildlife Scheme [DoWS]).

locularis, a 3-mm intestinal cestode parasite, primarily of red foxes but also more recently of raccoon dogs (Nyctereutes procyonoides) and occurring in many, but not all, European countries. The multicystic larval stage causes severe organ lesions in the rodent intermediary host (Fig. 1). Echinococcosis is a zoonosis and, as accidental intermediary hosts, infected humans develop alveolar echinococcosis after ingesting eggs of the parasite (Conraths and Deplazes 2015).

It is difficult to establish accurate prevalences of E. multilocularis in wildlife throughout Europe because surveillance methods across European countries are inconsistent. The number of human cases of alveolar echinococcosis gives an approximate indication of which countries are predominantly affected. Echinococcus multilocularis is spreading to western and northern Europe from eastern and central areas, where the parasite has long been present with higher prevalence. The western front of expansion in the past $5 \mathrm{yr}$ has been in the Netherlands and
France, probably as a result of red fox movements. Northern spread is evidenced from the finding of E. multilocularis in Denmark and Sweden (Wahlström et al. 2012). In suburban areas with coexistence of relatively high numbers of red foxes and humans, there is increasing risk of human exposure when a fox population is infected with E. multilocularis, especially in regions where awareness of the disease is low.

Infection with E. multilocularis is expected to continue to spread throughout Europe, affecting countries previously free of the pathogen. This is due to the natural movements of endemic wildlife, such as the red fox, and expansion of invasive species such as raccoon dogs. Additionally, translocation of wildlife, as occurred with the first introduction of E. multilocularis in England in beaver (Castor fiber) in 2010 (Barlow et al. 2011; Fig. 1 ), or transportation of other hosts such as domestic dogs (Umhang et al. 2014) between countries, may result in new regions of infection. Eradication of the disease is not 
feasible, but lowering the prevalence in the main definitive hosts can be achieved by strategic regional red fox deworming campaigns (Comte et al. 2013). This can be anticipated in several European countries in the future as a method to decrease the risk of human disease, particularly from contact with the wildlife hosts of the parasite (Piarroux et al. 2013; Gottstein et al. 2015).

\section{Hantavirus infections, by Dan Horton}

Hantaviruses (genus Orthohantavirus, family Hantaviridae) are maintained in rodent and insectivore populations nearly worldwide, with little or no clinical effect on the host (Kruger et al. 2015). Zoonotic hantaviruses reported in Europe include Puumala virus (PUUV), carried by bank voles (Myodes spp.), and Dobrava-Belgrade (DOBV) and Saaremaa (SAAV) viruses carried by field mice (Apodemus spp.). Transmitted to humans through inhalation of aerosolized excreta, bite of infected animals, or contact with contaminated surfaces, these viruses can cause a range of clinical syndromes, including hemorrhagic fever with renal syndrome (HFRS), with a variable case fatality rate $(<1 \%$ for SAAV and PUUV, up to $12 \%$ for DOBV; Vaheri et al. 2013). More than 3,000 HFRS cases were reported annually in 2000-09, with most cases from parts of Northern Europe (Finland, Sweden, Norway), Central Europe (Germany, Belgium and France), and the Balkan countries (Vaheri et al. 2013; Avsic Zupanc et al. 2014). This apparent trend of relatively high numbers of cases has continued since 2010, though accurate estimates are confounded by variation in surveillance intensity. In addition, some countries report high antibody prevalence despite low numbers of HFRS cases. Cyclical patterns of variable length (2-4 yr), with epidemics interspersed with periods of reduced numbers of cases, appear linked to rodent population density, possibly driven by climatic factors and food availability, but regional variation in the effect of climate on these outbreak patterns impairs the ability to predict epidemics using climatic factors (Roda Gracia et al. 2015).
Another zoonotic hantavirus, Seoul virus, has a global distribution thought to be due to spread of one of the reservoirs, the brown rat (Rattus norvegicus), through international shipping. Seoul virus has recently been detected in wild rats in the UK, France, and the Netherlands (Dupinay et al. 2014; VernerCarlsson et al. 2015). Tula virus (detected in Microtus spp.) has also been associated with isolated reports of human disease, but is considered to have lower zoonotic potential, and a related novel hantavirus, Tatenale virus, was recently detected in a field vole (Microtus agrestis) in the UK through targeted surveillance (Pounder et al. 2013). Several hantaviruses not associated with human disease have been detected in insectivores including: Asikkala virus in the Eurasian pygmy shrew (Sorex minutus), Laihia virus in the Eurasian water shrew (Neomys fodiens), and Seewis virus in the common shrew (Sorex araneus). More hantaviruses have been detected in nonrodent hosts, including bats, but their zoonotic significance is unknown. In addition, cases of hantavirus infections in humans acquired outside of Europe pose a potential but unqualified threat (Kruger et al. 2015). With improving diagnostic tests and increased surveillance, it is likely that the number of hantaviruses, and their known hosts and geographic ranges in Europe, will continue to increase.

\section{Hepatitis E virus infections, by Frederik Widén}

Hepatitis E is caused by Hepatitis E virus (HEV), a small, nonenveloped, single-stranded, positive-sense RNA virus in the Hepeviridae, with worldwide distribution. Current taxonomy (International Committee on Taxonomy of Viruses [ICTV] 2014) divides the family into two genera, Orthohepevirus with species A-D and Piscihepevirus with one species (Cutthroat Trout virus). Orthohepevirus is proposed to contain six or seven genotypes (gt). Genotypes (gt) 1 and 2 of Orthohepevirus A infect only humans and will not be described here. Genotypes 3 and 4 are zoonotic (Lu et al. 2006). Avian HEV (AHEV) is not zoonotic, infecting only poultry (Huang 
et al. 2004). The zoonotic capacity of other HEV species is unknown. The main wildlife host for gt 3 and 4 is the wild boar (Sus scrofa); for AHEV it is unknown. Disease due to HEV has been documented in humans (gt 1-4) and poultry (AHEV), with mild or subclinical signs in other animals.

The known host range of HEV has expanded dramatically since 2010; at that time it had been described in humans, domestic pigs (Sus scrofa domesticus), red deer, European roe deer (Capreolus capreolus), European rabbits, and wild boars as well as in several nonEuropean animal hosts (Pavio et al. 2010). Since 2010, it has also been detected in brown rats, black rats (Rattus rattus), domestic ferrets (Mustela putorius), farmed mink (Mustela lutreola), Old World leaf-nosed bats (Hipposideridae), vesper bats (Vespertilionidae), and European moose (Alces alces) (Johne et al. 2014). Hepatitis E virus has also been detected in feces of red foxes (Bodewes et al. 2013b) in the Netherlands, but it is unclear whether it was a true infection or if the virus originated from ingestion and subsequent excretion of infected prey. Serology suggests that HEV infects other animal species, but this needs to be confirmed by detection of virus or viral RNA. The detection of $\mathrm{HEV}$ in various animal species raises the question of its zoonotic capabilities. Hepatitis $\mathrm{E}$ virus in rabbits, for example, is closely related taxonomically to gt 3 , but forms a separate clade in phylogenetic trees. Nevertheless, rabbit HEV was detected in a human patient in France (Izopet et al. 2012), suggesting that these taxonomic similarities may also confer similar infectivity. Other recently detected HEV species are distantly related to gt $1-4$. For these new species, the zoonotic potential is uncertain. There is evidence that the same animal species can be infected with more than one HEV species. Brown rats can be infected by an HEV that seems to be specific for rats, but also by gt 3 . Therefore, it is important to be aware that recombination could occur in rats, and this may also be possible in other animals.

In the next decade, we anticipate that new HEV species will be detected in other animal hosts. With the expanding number of host species and HEV variants, taxonomy has had to be adapted. The zoonotic potential of newly detected HEV species is an important concern, but is difficult to assess. We hope that future research into the molecular biology of HEV will identify virulence markers and determine host range. This will improve our understanding of HEV circulating in wild animals and the potential virulence for humans.

\section{Filovirus infections, by Dan Horton}

Viruses in the family Filoviridae are infamous as the causative agents of hemorrhagic fever in humans, with mortality rates of up to 90\%. Zaire ebolavirus (ZEBOV) and Marburg marburgvirus (MARV) are the most frequently reported species and have been associated with sporadic outbreaks of disease in humans and nonhuman primates in Equatorial Africa. The recent outbreak of human Ebola virus disease in West Africa was unprecedented in size and distribution in comparison to previous outbreaks (Mari Saez et al. 2015). Although the level of supporting evidence varies between virus species, bats are considered the likely reservoir hosts for the filoviruses (Olival and Hayman 2014). Since the initial detection of Ebola virus RNA in three bat species in Africa, antibodies have been detected in at least nine species and, when selected species have been experimentally infected, they have not succumbed to disease but have shed virus (Olival and Hayman 2014). Longitudinal studies on the cavedwelling Egyptian fruit bat, Rousettus aegyptiacus, in Uganda provide compelling evidence of that species being a MARV reservoir (Amman et al. 2012), but similar support does not yet exist for ZEBOV (Olival and Hayman 2014). Recent circumstantial evidence has implicated an insectivorous bat species (Mops condylurus) as the primary source of the West African outbreak and, although antibodies have previously been detected in this species, no evidence for virus or antibodies was detected in bats from the location of the index human case (Mari Saez et al. 2015). 
Until recently, and with the exception of the apparently less-pathogenic Reston ebolavirus in Asia, it was believed that the filoviruses were restricted to Africa. European interest has mostly been directed at the risk of imported cases, rare laboratory infections, speculation about historical outbreaks, and preparedness for a perceived threat of deliberate misuse as a bioterrorist agent (Simons et al. 2014; Wolf et al. 2014). Imported cases include the original isolation of MARV in African green monkeys (Chlorocebus aethiops) imported from Uganda in 1967, contraction of MARV by a Dutch tourist through direct contact with bats in Africa and, more recently, imported cases from West Africa (Wolf et al. 2014).

However, in 2011, the novel filovirus species Lloviu cuevavirus was detected through investigation of a mass die-off of Spanish Schreiber's bats, Miniopterus schreiberseii (Negredo et al. 2011). The bats had pathology consistent with viral pneumonia, but causation of clinical disease has not been proven, and there were no associated reports of human disease. This discovery of a genetically distinct filovirus in Europe and the detection of ebolavirus antibodies in insectivorous bats in Asia supports the importance of more systematic surveillance in European bats to be aware of the potential emergence and spread of these dangerous zoonotic pathogens.

\section{Tularemia, by Gete Hestvik}

Tularemia is caused by the bacterium Francisella tularensis subsp. Holarctica and, with the exception of a few countries, it is distributed widely in Europe. Several transmission routes are possible via a variety of vectors such as mosquitos and ticks, direct contact with an infected animal, inhalation of bacteria-containing dust, or ingestion of contaminated food or water. Until 2010, tularemic disease had only been described in European brown and mountain hares (Lepus europaeus and Lepus timidus, respectively), European rabbits, and a few small rodents (Hestvik et al. 2015). However, in 2013 tularemia was described in a stone marten (Martes foina; Origgi et al. 2013). Recently, F. tularensis, or antibodies against it, was detected in a wider range of wildlife in Europe including several additional small rodent species, red foxes, wild boars, and raccoon dogs (Kuehn et al. 2013).

In 2013, tularemia re-emerged in the Netherlands in the European brown hare (Rijks et al. 2013) after 60 yr during which no cases had been reported in that country. Because tularemia is a well-established disease that can affect a wide range of hosts, it is likely to expand to involve more countries and animal species. Geographic expansion across Europe can also be expected in relation to climate change because vectors dependent on a warmer climate may establish in new areas and contribute to an increase in transmission of the bacteria (Vonesch et al. 2016). Disease modelling has predicted a prolongation of outbreak durations in endemic areas due to increased temperatures (Ryden et al. 2009). The proposed geographic expansion, longer outbreak periods, involvement of more animal species, and spread of vectors to new areas could, together, result in a higher human incidence of tularemia.

\section{Leishmania infantum infection, by Ezio Ferroglio}

Leishmaniasis is a complex of mammalian diseases caused by diphasic protozoans of the genus Leishmania, which complete their life cycle in two species: a phlebotomine sand fly vector and a mammalian host (Ferroglio et al. 2005). Leishmania infantum is traditionally endemic in the Mediterranean basin but, in the last decade, has also spread in regions of Europe with a continental climate (Ferroglio et al. 2005; Biglino et al. 2010). Traditionally, the domestic dog has been considered the main reservoir, but the possible role of wildlife as a reservoir has been suggested, particularly for wild carnivores (Millán et al. 2014), although there is also evidence that lagomorphs could maintain the parasite in a wildlife cycle.

Between 2009 and 2012, a leishmaniasis outbreak associated with lagomorphs occurred 
in the southwest of the province of Madrid (Spain), where at least 446 human cases were reported (Arce et al. 2013). In the same area, Iberian hares (Lepus granatensis) were infected by sand flies (Phlebotomus perniciosus; Molina et al. 2012), which are the main vector in most of the areas affected in Europe (Ferroglio et al. 2005; Durán-Martínez et al. 2013). A high prevalence of infection was seen in lagomorphs, with a mean of about $50 \%$ in Spain (Ruiz-Fons et al. 2013) in Iberian hares and European brown hares. Infection in lagomorphs has also been found in a continental area of Northern Italy with a high prevalence in European brown hares, wild European rabbits, and Eastern cottontail rabbits (Sylvilagus floridanus; E.F. unpubl.). On Montecristo Island in Italy, rodents such as black rats also maintain infection in the absence of carnivores (Zanet et al. 2014).

The use of pyrethroids is an effective option to control the spread of infection in dogs (the main reservoir), which decreases overall risk of infection (Ferroglio et al. 2008). However, wildlife reservoirs could negatively affect efforts to control the spread of infection and increase the risk of transmission to humans. In Europe, P. perniciosus is one of the most widespread sand flies, and is present in domestic/urban as well as wild areas, so it can easily maintain Leishmania infection in wild hosts and may be instrumental in spillover to domestic animals and humans, as the previously described Madrid outbreak demonstrated.

The role of wildlife in the circulation of Leishmania, and the spread of the infection to new areas of Europe with a continental climate, will increase the impact of this neglected parasite on public health.

\section{Rabies virus infection, by Dan Horton}

The elimination of fox rabies in Western Europe through extensive oral rabies vaccination (ORV) programs in the latter 20th Century was an unprecedented achievement in wildlife disease control (Freuling et al. 2013; Muller et al. 2015). Despite this initial success, wildlife rabies persists in parts of
Europe, with over 2,000 wildlife cases reported in the wider European region in 2015 including cases in several EU member states (World Health Organization [WHO] 2015).

Wildlife rabies in the EU: During 2010-15, numbers of reported wildlife rabies cases in the EU declined due to continued ORV (Muller et al. 2015). Baltic states reported no cases in wildlife in 2013, and the eastern EU member states of Romania, Poland, and Hungary reported relatively consistent but low numbers. Fewer than 150 wildlife rabies cases were reported across all EU member states in 2015 (WHO 2015). Challenges to complete elimination of wildlife rabies include bureaucratic and administrative obstacles, maintaining funding support, and coordinated vaccination across borders with countries where wildlife rabies persists (Muller et al. 2015).

In 2008, fox rabies was detected in Italy for the first time since 1997. The outbreak was controlled by ORV and, by 2012, Italy was again rabies free. However, in late 2012 rabies was reported in Greece for the first time since 1987, and cases were reported each year until 2015 (Tsiodras et al. 2013). Epidemiologic studies of rabies dynamics have suggested westward and southward spread in the Balkan peninsula. Surveillance varies by country and over time, meaning that although these recent epidemics are likely reintroductions, there is potential for undetected, low-level rabies persistence in some areas (Johnson et al. 2007; McElhinney et al. 2011; Picard-Meyer et al. 2013; Muller et al. 2015).

Wildlife rabies in countries bordering the $E U$ : Reported rabies cases in countries bordering the EU have been declining but remain high; for example, the Russian Federation, Ukraine, and Turkey collectively reported $>1,500$ cases of wildlife rabies in 2013 (WHO 2015). These regions, and countries in North Africa, the Middle East, and the Caucasus, also have dog rabies, suggesting complex disease epidemiology and further challenges for control (Horton et al. 2015).

Other wildlife reservoirs: After introduction into Western Russia for hunting in the 1920s, raccoon dogs spread westward and established 
in Eastern and Central Europe. Raccoon dogs are the second most frequently reported wildlife species with rabies in Europe (after red foxes). Fortunately, ORV strategies designed for foxes appear effective against raccoon dogs (Muller et al. 2015). There are also flourishing populations of North American raccoons (Procyon lotor), which were introduced into Germany and the Caucasus (Timm et al. 2016), and of small Indian mongooses (Herpestes auropunctatus) in Croatia (Barun et al. 2010). Both species are rabies reservoirs in other regions (North America and the Caribbean, respectively) and, although there have not been confirmed cases of rabies in these European populations, if rabies were introduced these species could serve as additional reservoirs and the pathogen could prove challenging to control (Vos et al. 2012; Zieger et al. 2014).

\section{Salmonella infections, by J. P. Duff}

Salmonella spp. are Gram-negative bacteria in the family Enterobacteriaceae that infect and cause disease in humans, livestock, pets, and wildlife. Some Salmonella spp. appear to be host-adapted to wild species in Europe, which serve as reservoirs, including $S$. enterica subsp. enterica ser. Enteritidis (phage type 11) in hedgehogs (Erinaceus europaeus; Gaffuri and Holmes 2012) and S. enterica subsp. enterica ser. Typhimurium (S. enterica ser. Typhimurium) in garden passerines (Lawson et al. 2014). Chiari et al. (2013) have also recorded $S$. enterica ser. Typhimurium and $S$. enterica subsp. diarizonae and subsp. houtenae infections in wild boar. Similar Salmonella spp. may be found in livestock and wildlife sharing the same environment (e.g., garden bird salmonellosis; Horton et al. 2013).

Wild species associated with livestock systems, in shared, contaminated environments, Feral Pigeons (Columba livia), and European Starlings (Sturnus vulgaris), are susceptible to salmonella infections from livestock and vice versa (Gaffuri and Holmes 2012); however, the extent to which this may occur is difficult to quantify. Passerine salmonellosis (garden bird salmonellosis), particu- larly in finches, sparrows, and buntings, causes disease and mortality; in Europe this has been widely associated with garden bird feeding stations (Gaffuri and Holmes 2012). Although human clinical disease has not been significant in terms of severity or prevalence, these infections are important because garden bird salmonellosis has, in the study period, been identified as a source of spillover disease in an extensive range of animal species including poultry, pets, domesticated species, wild species, and humans (Horton et al. 2013; Lawson et al. 2014). The prevalence of salmonellosis in passerines in England has declined since about 2009, for unknown reasons and, during this time, the prevalence of infection of these passerine-associated salmonellae in domestic animals has also declined.

\section{West Nile Virus infections, by Karoly Erdelyi}

West Nile virus (WNV) is a zoonotic flavivirus circulating in a wild bird-mosquito cycle in endemic and sporadically infected areas of Africa, Europe, the Americas, Australia, and Asia (Petersen et al. 2013). Varying degrees of disease and mortality are caused by WNV in several bird species, particularly birds of prey and corvids. European bird species are generally less susceptible to clinical WNV disease, with the possible exception of some birds of prey (e.g., Goshawks, Accipter gentilis; Bakonyi et al. 2013). Some reptiles (e.g., alligators) and amphibians (e.g., marsh frogs, Pelophylax ridibundus) infected with WNV develop disease with high levels of viremia. Mammals are generally considered dead-end hosts, but potential for WNV transmission has been identified in some North American squirrel species (Padgett et al. 2007). Due to the increased exposure of highly susceptible elderly people and patients with predisposing chronic conditions, human West Nile fever (WNF) poses a public health challenge in Europe and worldwide (Petersen et al. 2013t

Historically, European WNV circulation was characterized by short epidemics occurring predominantly in the Mediterranean 
area. This changed after the European expansion of the lineage $2 \mathrm{WNV}$ strain that was introduced to Hungary in 2004 (Petersen et al. 2013). Following its spread across Central Europe in 2008-09 (Bakonyi et al. 2013), a highly virulent variant of this WNV strain caused a major epidemic in Greece in 2010-13, appeared in humans and animals in Northern Italy in 2011 and caused another serious WNF outbreak in Serbia in 2012-13 (Hernández-Triana et al. 2014). The spatiotemporal pattern of these sequential events suggests that migratory bird species play a role in the dispersal of WNV from endemically infected areas. The exceptional potential for geographic spread of WNV by migratory birds is demonstrated by the North Italian emergence of the lineage 2 Volgograd strain previously found only in the Black Sea region (Ravagnan et al. 2015).

The presence of lineage 1 and $2 \mathrm{WNV}$ strains and Usutu virus in Northern Italy is a good example of the cocirculation of multiple flavivirus strains, an important feature of WNV epidemiology (Nikolay 2015). The virulence of the circulating lineage $2 \mathrm{WNV}$ strain has increased over the past $5 \mathrm{yr}$, resulting in the WNF epidemics with high fatality in Greece and Serbia (HernándezTriana et al. 2014). The uninterrupted circulation of the virus in Central Europe led to one of the longest WNV epidemics in the continent.

Monitoring of WNV in arthropod vectors has provided information on current geographic distribution, revealing both a northwestern (Southern Moravia [Czech Republic]) and a southwestern (northern Italy) expansion. From the wide range of competent mosquito vectors with a Europe-wide distribution, contemporary evidence is available for the primary vector role of Culex pipiens and additional involvement of Culex modestus, Oshlerotatus annulipes, and Coquillettidia richardii in WNV circulation (Szentpali-Gavaller et al. 2014; Rudolf et al. 2017). These developments indicate a potential for further westerly spread of WNV in the coming decade. As has been demonstrated by the focal epidemics of Usutu virus in Switzerland,
Germany, Czech Republic, France, and Belgium, adequate environmental conditions for circulation of $\mathrm{WNV}$ and other mosquito-borne flaviviruses may also exist in Western and even Northern Europe (Cadar et al. 2017). The potential northwestern expansion of WNV in Europe may pose unforeseen risks to endemic bird species.

The extent and severity of these potential future epidemics would depend on the virulence of the WNV strain and the stillundefined vector capacity of local mosquito populations. The dynamic epidemiology of WNV in Europe, forming a pattern of endemically infected core areas (Mediterranean coast, Carpathian basin) and newly emerging epidemic foci, necessitates continuous development and evaluation of WNV surveillance across Europe, which utilizes the most efficient tools for risk assessment and early warning.

\section{WILDLIFE PATHOGENS WITH PRIMARY IMPACTS ON LIVESTOCK HEALTH}

\section{African swine fever virus infections, by Iwona Markowska-Daniel}

African swine fever virus (ASFV, family Asfarviridae) infects domestic pigs (pigs), European wild boars, bushpigs (Potamochoerus spp.), warthogs (Phacochoerus spp.), and giant forest hogs (Hylochoerus spp.; Costard et al. 2013). Until 1957, ASF was restricted to Africa. In the 1960s, it spread to Portugal and Spain and after $>30 \mathrm{yr}$ was eradicated on the Iberian Peninsula. However, it has been endemic on the island of Sardinia since 1978 (Sánchez-Vizcaíno et al. 2013), and new cases in pigs and wild boars continue there. In 2007, after incursion into Georgia, ASFV spread rapidly in the Caucasus, the Russian Federation ( $\mathrm{RF}$ ), Ukraine, and Belarus, reaching the Eastern European (EE) countries in 2014 (Pejsak et al. 2014; Fig. 2). As of 1 January 2017, 23 cases of ASF in pigs and 161 in wild boars were detected in northeastern Poland, near the border with Belarus (Animal Disease Notification System [ADNS] 2017a). Cases reported in Estonia were 24 pigs and 1,816 wild boars, in Latvia 35 pigs and 1,766 boars, 


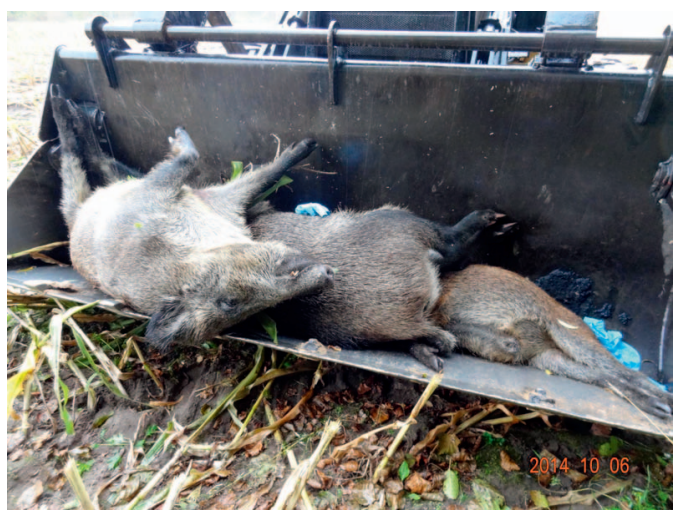

Figure 2. Removal of the carcasses of dead wild boars infected with African swine fever virus, Kolonia Zaleszany, Poland, October 2014 (photograph courtesy of Joanna Piekut).

and in Lithuania 38 pigs and 459 boars (ADNS 2017b). Ukraine declared 147 outbreaks to the OIE in pigs and wild boars (OIE 2013). Two new cases were also reported in Moldavia in 2016 and ASF continued to be detected in the RF.

Wild boars are more severely affected than are pigs. Free-ranging, infected wild boars can move the disease through natural corridors, playing an important role in ASF spread in $\mathrm{EE}$, as shown by sequence analysis of ASFV isolates from the first cases in EE (Gallardo et al. 2014). The first cases of ASF in the EU were detected by passive surveillance of wild boars found dead; the number of ASF cases in dead wild boars was significantly higher than in hunted, apparently healthy boars (Pejsak and Markowska-Daniel 2015).

Experimental studies showed that currently circulating ASFV is highly virulent, causing death in most infected wild boars before they develop detectable antibody response (OIE 2013). This was also demonstrated in field surveys in Latvia and Poland, where only a very low percentage of living infected wild boars were antibody positive. Moreover, in natural conditions, although the virus shows high virulence and very high lethality, it demonstrates relatively low infectivity, suggesting the disease is not highly contagious.
A detailed spatiotemporal analysis of ASF in wild boars in the affected region of Poland, during February-December 2014, revealed that the annual movement of the ASF disease front was approximately $30 \mathrm{~km}$, or almost 3 km/mo (Pejsak and Markowska-Daniel 2015). It also demonstrated that the population density of wild boars was sufficient to support significant further spread of ASF. A wild boar density of about $2 / \mathrm{km}^{2}$ favors sustainable circulation of ASFV in boars. However, in Poland, in 2014 the density of wild boars in the affected region was around $1.5 / \mathrm{km}^{2}$. From 2014-15 the density in this region decreased by $25 \%$ and currently there are 0.3-0.5 boars $/ \mathrm{km}^{2}$ (Pejsak and MarkowskaDaniel 2015). Nevertheless, ASF continues to be detected in wild boars in the region, suggesting that once ASF is established in an area, high wild boar population density is not required for continued viral circulation. This may be due to the presence of infected boar carcasses, which may serve as a source of virus

All ASFV isolates are from EE genotype II, suggesting one virus introduction. The sequence of the intergenic (noncoding) region demonstrated insertion of an additional tandem repeat sequence in ASFV isolates from Belarus from 2013 and in ASFV from Lithuania and Poland from 2014 , which is absent in Russian isolates from 2012 and from Georgian isolates from 2007 (Gallardo et al. 2014). This suggests possible genetic variability among ASFVs circulating in EE. It was highly likely that ASFV was introduced into EE by wild boars entering Lithuania and Poland from Belarus (Gallardo et al. 2014).

It is likely that ASFV will spread further with wild boars into new regions and countries in Europe. Long-term disease management and control, based for example on noninvasive sampling (oral fluid, feces), should focus on surveillance of wild boars and pigs to enable early detection; strict biosecurity measures can then be introduced to prevent ASFV spread in pigs. Further characterization of the isolates currently 


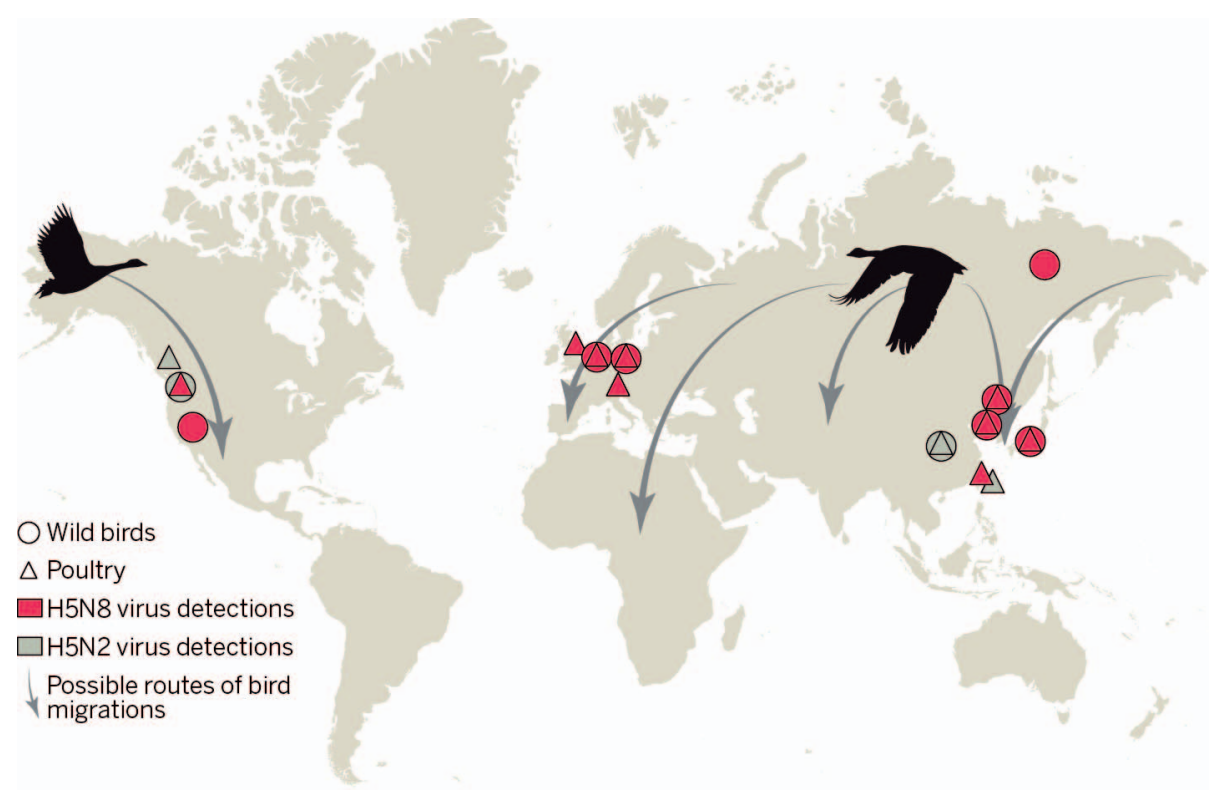

Figure 3. The 2014 H5N2 and H5N8 (Avian influenza) virus detection in poultry and wild birds. The almost simultaneous detection of closely related viruses in Asia, Europe, and North America suggests linkage with wild bird migration via a large region in Russia (reproduced with permission from Verhagen et al. [2015]).

circulating and research into their evolution should be prioritized.

\section{Avian influenza virus infections in wild birds, by Thijs Kuiken}

Avian influenza A viruses predominantly infect waterbirds of the orders Anseriformes (mainly ducks, geese, and swans) and Charadriiformes (mainly gulls, terns, and waders). Such infections of wild waterbirds occur widely in Europe and almost exclusively involve low pathogenic avian influenza (LPAI) viruses. Exceptions are highly pathogenic avian influenza (HPAI) viruses of the subtypes H5N1 and H5N8. Following the incursion of HPAI H5N1 virus into Europe, particularly in the winter of 2005-06, the reported detection of HPAI H5N1 virus in wild birds became less frequent, with the last published report in a Common Buzzard (Buteo buteo) from Bulgaria in 2010 (Reid et al. 2010), prior to the outbreak of HPAI H5N8 in a range of wild bird species in 2016. No further cases of HPAI H5N1 have been detected in poultry or wild birds in Europe since 2010 (OIE 2017).
However, in November 2014, HPAI H5N8 virus emerged in Europe (Verhagen et al. 2015; Fig. 3). This virus, which had inherited several gene segments from HPAI H5N1 viruses of the A/Goose/Guangdong/1/1996 lineage, was first detected in China in 2010 (Lycett et al. 2016). In September 2014, the virus was detected in a hunter-shot Eurasian Wigeon (Anas penelope) in northeast Russia (Lycett et al. 2016).

The virus spread to Europe soon afterwards. Between November 2014 and February 2015, HPAI H5N8 virus was detected on poultry farms and other holdings as well as in a few wild waterbirds in Germany, the Netherlands, the UK, Italy, and Hungary, and in two Mute Swans (Cygnus olor) in Sweden (Lycett et al. 2016). In the same period, the virus spread to poultry farms and wild birds in western and central North America (Lycett et al. 2016). A global analysis of $\mathrm{H} 5 \mathrm{~N} 8$ viral sequences, epidemiologic investigations, waterfowl migration, and poultry trade indicated that the main routes of large-scale geographic spread of HPAI H5N8 virus were likely not via trade in poultry or 
poultry products, human travel, or transport of materials associated with the poultry industry. Instead, HPAI H5N8 virus likely spread via long-distance flights of infected wild birds, first in spring 2014 from South Korea to their northern breeding grounds and then in autumn 2014 from these breeding grounds along migration routes and to wintering sites in North America and Europe (Lycett et al. 2016). In November 2016, HPAI H5N8 virus again emerged in Europe (Pohlmann et al. 2017) and, by March 2017, had been reported in 24 European countries (OIE 2017).

The potential for virus exchange between poultry and wild birds is likely to increase as a result of rapidly growing global poultry production (Bruinsma 2003) and increasing endemicity of avian influenza virus in poultry (Alexander 2007). Also, production of organic poultry in the EU has increased nearly fourfold from 6.5 million in 2003 to 33.6 million in 2014 (European Commission 2016; Table 7). This indicates an increase in the number of free-range (outdoor) poultry farms, which are at higher risk from incursion of LPAIV than are closed farms (Van Der Goot et al. 2013). Therefore, more avian influenza viruses are likely to spill over from poultry to wild birds and vice versa in the next decade unless biosecurity is improved.

\section{Bluetongue virus (BTV) infections, by Francisco Ruiz-Fons}

Bluetongue is a disease of ruminants caused by bluetongue virus (BTV), a vector-borne Orbivirus. The main wildlife hosts in Europe include several wild ruminant species, which do not show clinical signs upon infection, except for one report in a game reserve of Spanish mouflons (Ovis orientalis orientalis), a close relative of domestic sheep (Ovis aries) (Fernandez-Pacheco et al. 2008). However, on the basis of demographic status, geographic distribution, behavioral patterns, and incidence of BTV, the red deer appears to be the most susceptible wild ruminant and may therefore represent a wildlife reservoir in Europe (Ruiz-Fons et al. 2008), particularly southern Europe (Rossi et al. 2014).
The decade prior to 2015 saw frequent incursions of BTV into Europe, and almost every wild ruminant species investigated on the continent was found to be susceptible to infection. The Pyrenean chamois (Rupicapra pyrenaica, subsp. pyrenaica, parve and orna$t a)$ and the Alpine chamois ( $R$. rupicapra) were recently added to this list (Ruiz-Fons et al. 2014).

The geographic expansion of BTV in wild ruminants is similar to that reported in domestic ruminants (Ruiz-Fons et al. 2008; Rossi et al. 2014), which are the main reservoirs for BTV in Europe. Efforts to control its spread in livestock significantly reduced the geographic range of BTV in livestock and perhaps in wildlife (Rossi et al. 2014). This reduction in range was evident for most of central and northern Europe (UK, the Netherlands, Belgium, Sweden, Germany) but not for southern Europe (Portugal, Spain, France, Italy, Croatia, Greece, Bulgaria). Currently, BTV is endemic in southern European livestock and red deer populations. Southern Europe also experiences annual incursions of BTV-infected midges from northern Africa and the Middle East, further complicating BTV control in the region.

Future studies of BTV in European wildlife should definitively indicate whether BTV transmission at the livestock-wildlife interface occurs and the extent to which wildlife in southern Europe maintain BTV, as well as determining its vectors. This scenario of wildlife maintenance of BTV in southern Europe may be associated with risks of temporal incursions of BTV into central and northern Europe through host or vector movements. If climate change results in more favorable conditions for BTV persistence in vector species in central and northern Europe, the range of endemic BTV may expand northward.

\section{Bovine Tuberculosis, by Jean Hars and Dolores Gavier-Widén}

Bovine tuberculosis (bTB), caused by $M y$ cobacterium bovis or M. caprae, is a zoonotic disease with a wide host range. The main wildlife hosts in Europe are European bad- 
gers (Meles meles), wild boars, and red deer; their epidemiologic role as maintenance or spillover host varies regionally (Gavier-Widen et al. 2009).

In wildlife, bTB occurs in focal areas in the British Isles (but more extensively in southwestern England, Wales, and Ireland), the Iberian Peninsula, the Alps, France, and Eastern Europe. A surveillance program for bTB in free-ranging wildlife ("the Sylvatub system"; https://www.plateforme-esa.fr/ sylvatub) launched in France in 2011 determined that, by 2015 , bTB was present in wildlife in 11 French departments but was observed only in bovine-infected areas, and the genotypes of $M$. bovis isolated from cattle were identical to those isolated from wildlife in the same areas. Badgers and wild boars had the highest infection rates and $M$. bovis was also isolated from four roe deer in the Dordogne. In several areas in France, bTB has evolved in a multihost system involving cattle, badgers, wild boars, and red deer (Hauer et al. 2015).

Mycobacterium caprae has been primarily associated with disseminated bTB in goats. However, in central Europe it has recently emerged in cattle, wild boars, and red deer. In countries considered essentially free of bTB (the vast majority of livestock in Europe is bTB free), such as Austria, Germany, and the Czech Republic, a large proportion of bTB cases in free-ranging red deer and domestic cattle are caused by $M$. caprae (Rodríguez et al. 2011). Several human cases due to $M$. caprae have been reported in these countries of central Europe (Prodinger et al. 2014) and in Spain (Rodriguez et al. 2009) and France (Aime et al. 2012). In a study of bTB in wildlife in the Alps, Fink et al. (2015) investigated 1,655 hunted red deer and found high M. caprae prevalence, primarily in Austria, thought to be facilitated by aggregations of the population due to supplementary feeding.

In the Bieszczady Mountains, southeastern Poland, bTB affected a herd of free-living European bison (Bison bonasus caucasicus; Krajewska et al. 2014). The herd was depopulated in 2012; however, in the same year, a wild boar from the same area was found infected with the same spoligotype identified in the bison (Krajewska et al. 2014).

Mycobacterium bovis in livestock has been eradicated or controlled in large parts of Europe, but remains a challenge in areas where there are wildlife reservoirs. Once bTB is established endemically in wildlife populations, eradication is very difficult. Furthermore, increase of bTB in cattle in many parts of Europe has been attributed to wildlife (wild boars, red deer, and badgers) as a possible source of infection.

\section{Brucellosis, by J. Godfroid}

Brucellosis is a zoonotic disease with a significant global impact on animal and human health. Brucella melitensis, Brucella abortus, and Brucella suis, causative agents of small ruminant, bovine, and swine brucellosis, respectively, are important animal and human pathogens. Two novel transmission scenarios at the wildlife/livestock/human interface have recently been described: 1) In France, $B$. melitensis spilled over from a previously unrecognized wildlife reservoir-the Alpine ibex (Capra ibex) - to cattle, and from cattle to humans, via human consumption of unpasteurized cheese (Mick et al. 2014); 2) In Poland (Szulowski et al. 2013) and Belgium (Fretin et al. 2013), B. suis biovar 2 spilled over from wild boars, a recognized wildlife reservoir, to cattle. However, while B. melitensis is pathogenic for cattle (abortions have been described), B. suis biovar 2 is not. All biovars of $B$. melitensis are zoonotic. Brucella suis biovar 2 is not a true pathogen for humans, in contrast to B. suis biovars 1,3 and 4, which are all zoonotic (Godfroid et al. 2011). In the EU, 354 confirmed brucellosis cases were reported in 2014, and the highest rates were reported by southern Member States that are not yet officially free of bovine brucellosis or B. melitensis (European Centre for Disease Prevention and Control [ECDC] 2017).

Brucella microti was isolated from wild boars without clinical disease (Rónai et al. 2015). The bacterium was also isolated from 
common voles (Microtus arvalis; Scholz et al. 2008) and from red foxes (Scholz et al. 2009. Recently, it has been shown that novel Brucella species are distributed among exotic frogs worldwide and found in frogs housed in a tropical animal collection in Europe (Scholz et al. 2016). This followed reports of the isolation of Brucella from an African bullfrog (Pyxicephalus adspersus) at a quarantine center in Germany and from a big-eyed tree frog (Leptopelis vermiculatus) from a pet shop in Germany (Eisenberg et al. 2012). Although it is likely that these Brucella spp. infected their hosts before they were imported, these cases emphasize the importance of careful screening of imported wildlife to avoid importation of pathogens of risk to animal and human populations.

In 2016, a 12th Brucella species, Brucella vulpis sp. nov., was isolated from mandibular lymph nodes of red foxes in Austria (Scholz et al. 2016). This is the second new Brucella species recently isolated from red foxes. More spillover events from wildlife to livestock, and possibly from wildlife to humans, are likely, particularly from unrecognized wildlife reservoirs of Brucella spp. Likewise, new Brucella spp. may be described. We believe the most significant research findings are the isolation of Brucella spp. from the environment and from poikilothermic species (frogs), which represents a paradigm shift in our understanding of Brucella infection biology. Given that the host range of Brucella spp. has increased to include poikilotherms, the presence of Brucella in the marine food web, including fish, must now be investigated. In this context, fish were potential sources of Brucella pinnepidialis infection for seals (Lambourn et al. 2013; Nymo et al. 2013).

\section{Chronic wasting disease, by Dolores Gavier-Widén}

Chronic wasting disease (CWD) is a transmissible spongiform encephalopathy (TSE), a chronic neurodegenerative infectious prion disease of free-ranging and captive cervids. Initially, CWD was thought to be restricted to North America until it was introduced to South Korea via infected elk from Canada (Sohn et al. 2002). In North America, CWD naturally affected mule deer (Odocoileus hemionus hemionus), white-tailed deer (Odocoileus virginianus), Rocky Mountain elk (Cervus elaphus nelsoni), and Shira's moose (Alces shirasi) (Gavier-Widen 2012).

In 2006-10, Andreoletti et al. (2010) screened 3,274 farmed cervids and 10,049 wild cervids in the EU for CWD and other TSEs; all were negative. Then, in March 2016, a 3-4-yrold female wild reindeer (Rangifer tarandus tarandus) in the Nordfjella mountain area in Norway was diagnosed with CWD (Benestad et al. 2016). This was the first detection of CWD in Europe, and its first detection in a reindeer. In May 2016, a 13-yr-old female European moose in Norway (in Selbu, South Trøndelag County), about $300 \mathrm{~km}$ northeast from the reindeer case and showing abnormal behavior and poor body condition, was euthanized and diagnosed with CWD (Vitenskapskomiteen for mattrygghet [Norwegian Scientific Committee for Food Safety; VKM] 2016). Necropsy of another old female moose found dead in the same area revealed traumatic injuries in the thorax and the moose was positive for CWD (VKM 2016).

Norway immediately implemented an intensive surveillance program. About 29,000 animals of four species (reindeer, red deer, roe deer, and moose) were tested by November 2017, and CWD was detected in eight wild reindeer, three moose, and one red deer (Norwegian Veterinary Institute [NVI] 2018). The clinical, pathologic, and molecular features in the reindeer were similar to CWD in North America but differed from the moose and red deer in Norway in in that some characteristics were consistent with atypical prion disease, and the cases are preliminarily referred to as "atypical CWD." Ongoing investigations will characterize the strain(s) of prions involved in Norway. Eradication and control measures in Norway include depopulation of the entire reindeer herd affected, about 2,000 wild reindeer, and increased surveillance (VKM 2017).

The source of CWD in Norway has not been identified (VKM 2016). The geographic extent of infection in Europe and the prevalence and full range of cervid species affected 
are not known because limited surveillance has been conducted. The finding of CWD in Europe creates significant concern for several reasons. There is the potential for a substantial impact on health in populations of freeranging cervids. Moreover, once CWD is well established in a cervid population and environmental contamination occurs, eradication is considered unfeasible. If CWD becomes widespread, the economic impact on the hunting industry can be high and, if CWD enters the farmed cervid population, there could be considerable negative effects on the cervid farming industry.

The finding of CWD in reindeer suggests that reindeer are naturally susceptible to CWD. There is some contact between wild reindeer and semidomesticated reindeer and between reindeer and other cervids focally in several locations in Europe. Reindeer herding is a tradition and a main source of subsistence for the Sami people in Fennoscandia. Therefore, CWD would have a significant socioeconomic impact if it enters the semidomesticated reindeer populations. Reindeer management is normally seminomadic, in which the reindeer are moved between winter and summer pastures and even across national borders.

Even though CWD has not been known to affect humans, uncertainties about the biologic behavior of prions remain. The risk for humans to contract CWD is classified as very low (very rare, but cannot be excluded); nevertheless, measures to avoid or diminish exposure to humans (e.g., by avoiding consumption of meat from CWD-infected animals) are recommended (VKM 2016).

A better understanding of the occurrence and spread of CWD in Europe is needed to design control and management strategies. Therefore, the first and most urgent step is intensive surveillance with specific testing for CWD

\section{Schmallenberg virus infections, by Erik Ågren}

Schmallenberg virus (SBV), an orthobunyavirus, is an emerging pathogen in Europe spread by biting midge (Culicoides spp.) vectors. Ruminants (cattle, sheep, and goats) and alpacas (Vicugna pacos) are susceptible to infection (Wernike et al. 2015). Mild clinical disease occurs in adult domestic ruminants, but if a dam is infected for the first time while pregnant, transplacental infection may result in abortion or birth of malformed or weak offspring. Typical congenital malformations affect the limbs and skeleton (arthogryposis, kyphosis, scoliosis, lordosis, and brachygnathia) and the central nervous system (hydranencephaly, porencephaly, cerebellar hypoplasia, hypoplasia of the brainstem, and spinal cord; Wernike et al. 2015).

Schmallenberg virus emerged in central Europe in 2011 and spread rapidly throughout Europe via wind-dispersed, infected midges (Linden et al. 2012). Wildlife infection can potentially occur in areas where livestock are infected. Surveillance of SBV in wildlife has been sporadic, but investigators have detected antibodies against SBV in most European wild ruminants, both free-ranging and farmed, especially cervids (Capreolus, Alces, Cervus elaphus, and Dama dama) but also in mouflon (Ovis orientalis), chamois (Rupricapra spp.), Alpine ibex, and wild boar (Larska et al. 2013; Laloy et al. 2014; Rossi et al. 2015). There are no reports of fetal malformations or reproductive losses resulting from SBV infection in wildlife; however, there are findings of wildlife stillbirths and abortions in the field but they are relatively rare. In northern European cervids, rut and pregnancy occur late in the year, when midge activity has generally ceased because temperatures are low, whereas in central and southern Europe some deer species will be pregnant when midges are active. Evidence to date suggests that cervids and other wild ruminants are susceptible to SBV infection, but clinical disease has not been described in these species (Rossi et al. 2015).

\section{WILDLIFE PATHOGENS WITH PRIMARY IMPACTS ON WILDLIFE CONSERVATION AND BIODIVERSITY}

\section{Amphibian ranavirus infections, by S. J. Price}

Amphibian-like ranaviruses (family Iridoviridae) cause a systemic, hemorrhagic disease 


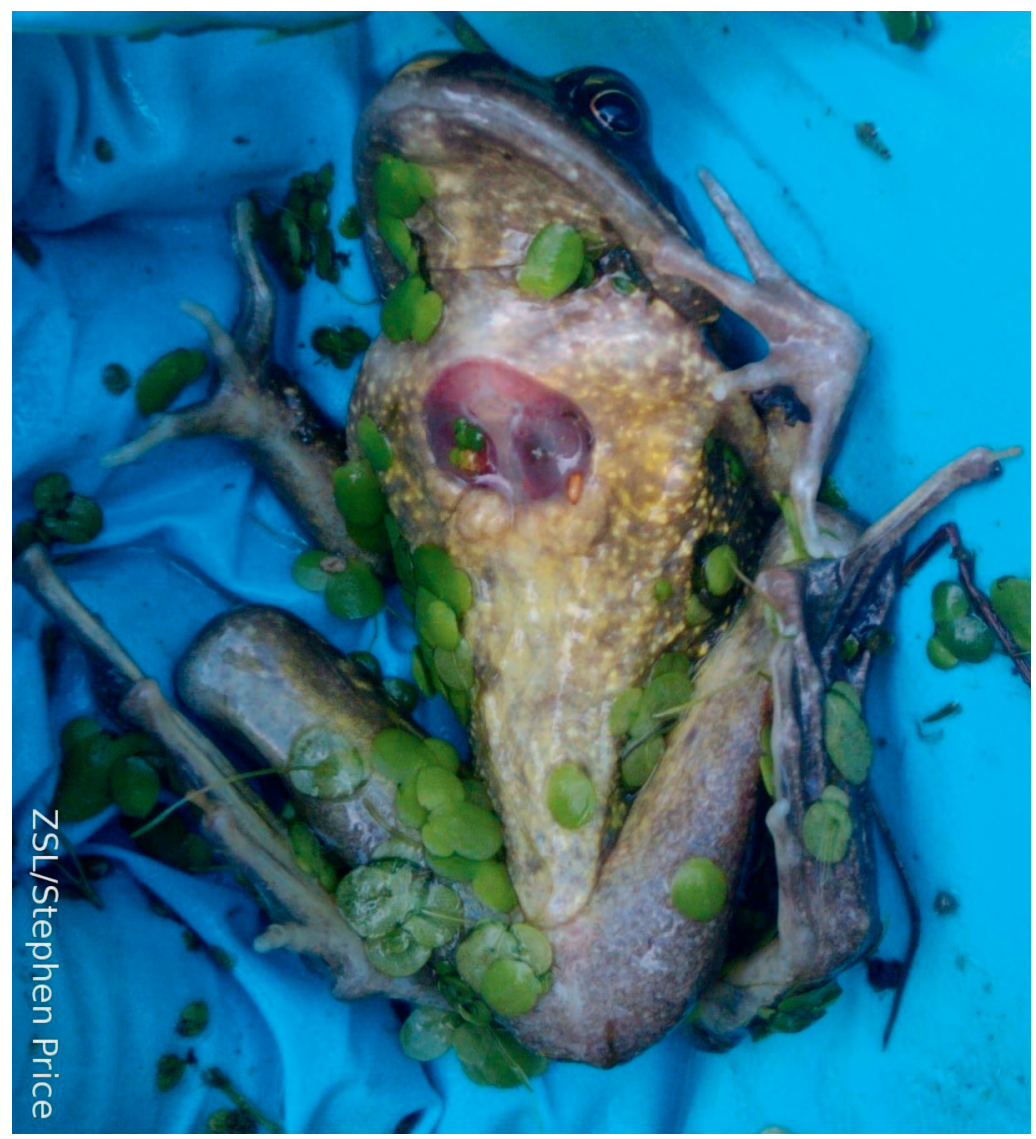

Figure 4. A live, adult common frog (Rana temporaria) experiencing emaciation and severe ulceration during a ranavirus outbreak in a British garden pond, June 2010 (photograph courtesy of Stephen Price).

of amphibians that can also affect reptiles and fish, and they are associated with massmortality events on five continents (Gray et al. 2009). Mass die-offs of European common frogs (Rana temporaria) in the UK, due to a ranavirus (Fig. 4), have been detected for approximately 25 yr (Cunningham et al. 1996), and there are older records of similar infections in frogs in the former Yugoslavia (now Croatia; Fijan et al. 1991) as well as in European fish. More recently, Europe has been the focus of a newly emerging ranavirus lineage.

Since 2010, common midwife toad virus and related viruses (CMTV-like) are ranaviruses that have been reported at several locations in Europe in an increasing number of host species and with severe impacts. Multihost amphibian die-offs in Picos de
Europa National Park, Spain, have been caused by CMTV since 2005 and have since caused the collapse of amphibian communities there (Price et al. 2014). At another site in Spain, the related Bosca's newt virus has also caused severe mortality events since 2010, affecting two species of newt and spilling over into viperine watersnakes (Natrix maura; Price et al. 2014). Following the events observed in Spain, amphibian die-offs were detected in Denmark, Belgium, the Netherlands, Germany, France, and Portugal (Duffus et al. 2015) involving viruses provisionally classed as CMTV-like based on limited sequence data. Another lineage of ranavirus (FV3-like) has caused serious declines of common UK frogs (Teacher et al. 2010), and experimental data suggest that UK viruses use the common frog as a primary host, with lower 
prevalence and disease severity in the common toad (Bufo; Duffus et al. 2014). This contrasts with observations of the extremely generalist CMTV-like viruses in Spain.

The severe effects and observed host range of ranaviruses in Spain has increased awareness of the threat to biodiversity posed by ranaviruses. As multihost pathogens that sometimes exhibit frequency-dependent transmission, they can drive population extirpations. In addition, sporadic records of infections in reptiles hint at a greater threat for reptiles than previously recognized. There is also increasing support for a role for humans in ranavirus emergence through the amphibian trade. In some regions, ranaviruses may have been associated with amphibians for millions of years while, in others, virus diversity suggests a modern layer of virus movement; in addition, ranaviruses have been found at high prevalence among traded animals. However, there remains a general lack of knowledge about potential modes of spread and impacts of ranavirus infections, and the research community must strive to generate data to inform surveillance and control efforts.

\section{Chytridiomycosis, by An Martel and Frank Pasmans}

Although a variety of factors are involved in amphibian declines worldwide, fungal chytridiomycosis is one of the major infectious diseases involved and has resulted in the extirpation of $>40 \%$ of amphibian species in areas of Central America and widespread losses across Europe, Australia, and North America. The first known etiologic agent of amphibian chytridiomycosis, Batrachochytrium dendrobatidis $(B d)$, causes disease in a variety of amphibian species of the three orders-frogs and toads (Anura), salamanders and newts (Urodela), and caecilians (Gymnophiona), and has triggered significant declines in over 200 amphibian species including several suspected extinctions in recent decades (Skerratt et al. 2007). European amphibians have heterogeneous responses to $B d$ exposure. Some species are susceptible to both infection and mortality attributable to chytridiomycosis, others seem less likely to suffer from either, and still others are refractory to infection (Pasmans et al. 2013). At present, $B d$ is widespread across Europe, where the general pattern appears to be a coexistence steady state within amphibian communities (Balá et al. 2014; Spitzen-van der Sluijs et al. 2014). In Europe, $B d$-driven amphibian declines may be limited to foci in the Pyrenees and Spain. Because Bd infection dynamics appear to be largely driven by environmental determinants (Schmeller et al. 2014; Spitzen-van der Sluijs et al. 2014), the current state of endemism may shift toward a less favorable, epidemic scenario.

Recently, a novel chytrid fungus, Batrachochytrium salamandrivorans (Bsal) has brought European salamander populations to the edge of extirpation (Martel et al. 2013). The fungus was likely introduced from Asia by infected amphibians (Martel et al. 2014) and the pet trade is the most plausible mechanism (Nguyen et al. 2017). Experiments demonstrated that frogs and toads are not susceptible to disease but can be infectious carriers (Stegen et al. 2017). Salamanders can be resistant (no infection, no disease), tolerant (infection in the absence of disease), susceptible (infection resulting in clinical disease with possibility of subsequent recovery), or highly susceptible (infection resulting in lethal disease). The highly susceptible fire salamander (Salamandra salamandra), currently the most affected species, cannot mount immunity after previous exposure (Stegen et al. 2017; Fig. 5) whereas in Asia, Bsal appears to be endemic, in Europe the fungus is exclusively associated with disease epidemics, and most European salamander taxa have died shortly after experimental exposure (Martel et al. 2014). Currently outbreaks occur in areas in the Netherlands, Belgium, and Germany (Spitzen-van der Sluijs et al. 2014). Because there are no natural barriers in mainland Europe that can prevent its spread, Bsal it is a serious threat to European salamander diversity.

Counteracting the impact of chytridiomycosis on amphibian populations is a major challenge. For $B d$, immunization (McMahon 


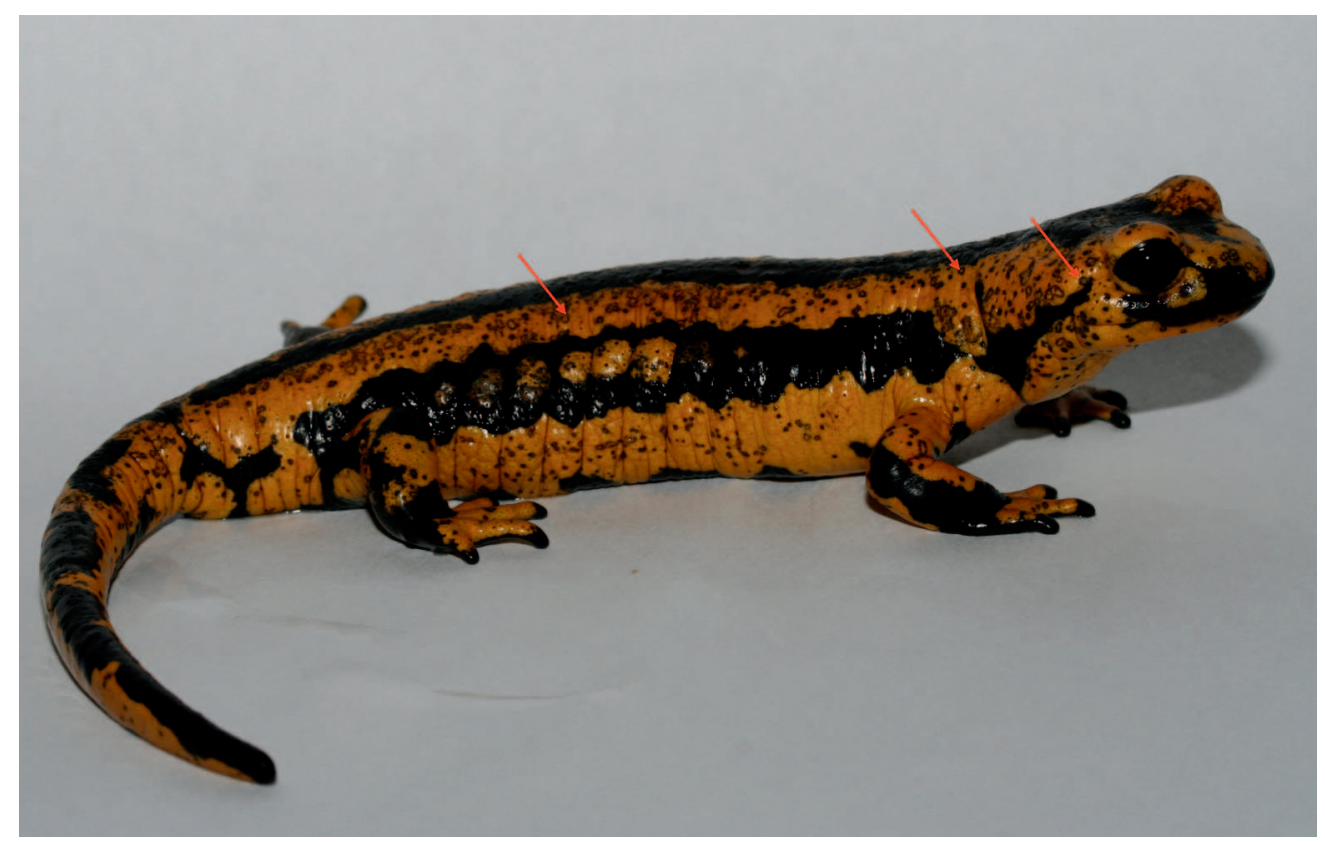

Figure 5. A fire salamander (Salamandra salamandra) in Merelbeke, Belgium, April 2017, shows severe lesions of Batrachchytrium salamandrivorans infection, visible as numerous small skin ulcerations with a black margin (arrows). Photograph courtesy of Frank Pasman.

et al. 2014), disinfection (Bosch et al. 2015), and use of biocontrol (e.g., probiotics or predatory microorganisms; Schmeller et al. 2014) offer some perspectives for in situ mitigation. For Bsal, mitigation is further complicated by the production of encysted spores that remain infective for a long time and are resistant to predation (Stegen et al. 2017).

\section{Canine distemper virus infections, by M.-P. Ryser- Degiorgis}

Canine distemper (CD), caused by canine distemper virus (CDV), is typically a disease of carnivores. However, species of artiodactyls, rodents, proboscidea, and primates were also found to be susceptible (Martinez-Gutierrez and Ruiz-Saenz 2016). The detection of CDV in fleas from an infected mink raised questions regarding the potential role of blood feeding insects a role in the horizontal transmission of CDV (Trebbien et al. 2014).

Various CDV strains have occurred widely in European wildlife for several decades. Yet, over the past $10 \mathrm{yr}$, CD has emerged in multiple hosts in various parts of the continent, causing high mortality in common species such as the red fox and threatening the conservation of endangered species including the Iberian lynx (Lynx pardinus; Meli et al. 2010) and the grey wolf in Italy (Canis lupus; Di Sabatino et al. 2014).

Since 2006, a major epidemic has extended through Austria, northern Italy, Liechtenstein, Switzerland, Germany, and Denmark, killing numerous foxes, stone martens (Martes foina), and badgers as well as an increasing number of free-ranging and captive wild and domestic species (Origgi et al. 2012; Trebbien et al. 2014). These have included domestic dogs (Martella et al. 2010; Origgi et al. 2012), freeranging Eurasian lynx (Lynx lynx; Origgi et al. 2012), captive Asian marmots (Marmota caudata), and a domestic cat (Felis catus) coinfected with an orthopoxvirus (Origgi et al. 2013: Wiener et al. 2013). From 2012-13, CD affected raccoons in Berlin (Rentería-Solís et al. 2014); in paralleh a large outbreak occurred in mink (Neovison vison) farms, free-ranging red foxes, ferrets, and raccoon 


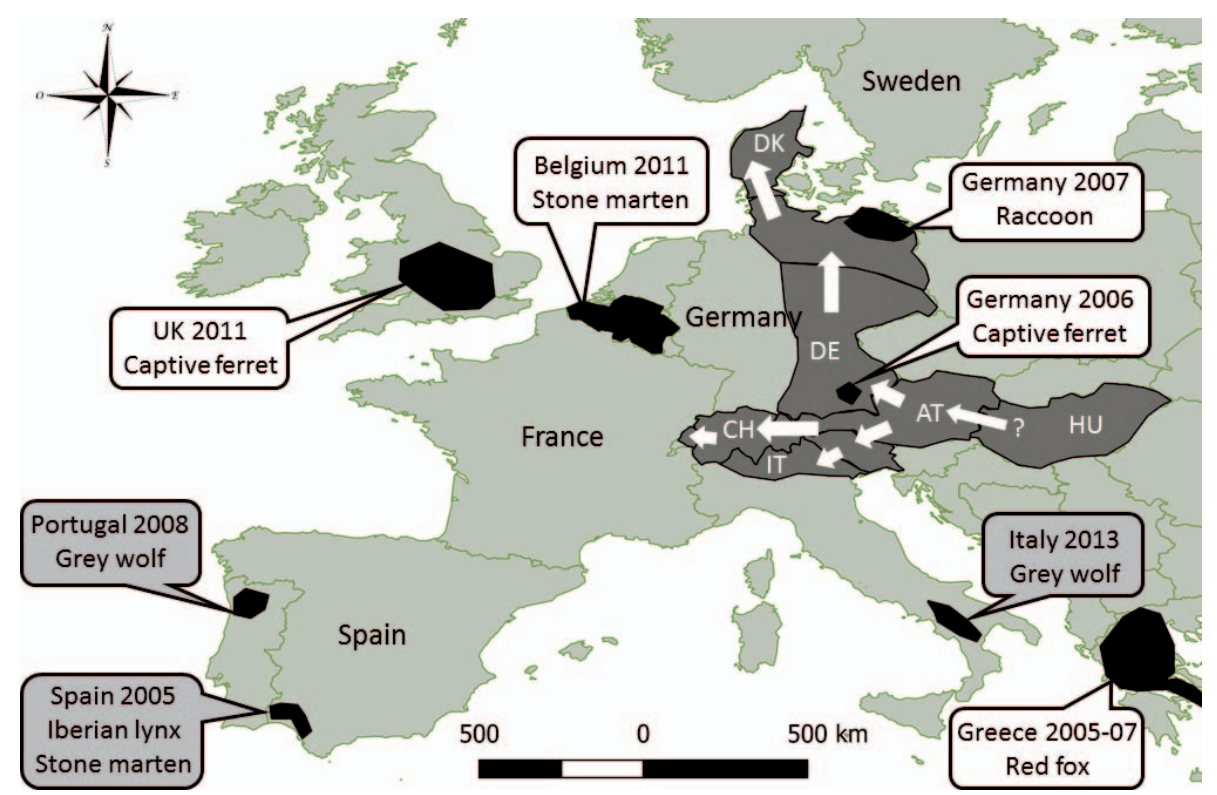

Figure 6. Outbreaks of Canine distemper in wildlife reported in the scientific literature. As not all areas or outbreaks were specified, the map may be inaccurate. Unless otherwise specified, affected animals were freeranging. Black areas depict independent local outbreaks; those with grey legend boxes were of suspected domestic dog (Canis lupus familiaris) origin. Dark grey areas refer to a transnational epidemic that likely started in Hungary (HU), where a diseased domestic dog was documented in 2004, and expanded over Austria (AT), southeastern Germany (DE), and northern Italy (IT) in 2006-08, Liechtenstein and Switzerland in 2009, northeastern Germany, and finally Denmark (DK) in 2012 (see white arrows), with cases continuing to occur. Although red foxes (Vulpes vulpes) and badgers (Meles meles) are the most affected species, increasing numbers of other hosts were recorded as the epidemic front progressed west and north (figure by Marie-Pierre RyserDegiorgis).

dogs in Denmark (Trebbien et al. 2014). In addition to evidence from the geographic pattern of spread of CD, molecular studies have shown that strains isolated from different hosts and geographic areas during this epidemic wave all belonged to the European lineage and were identical or very closely related (Origgi et al. 2012, 2013; RenteríaSolís et al. 2014; Trebbien et al. 2014). This finding contrasts with repeated documentation of the coexistence of multiple strains in the same geographic areas and time periods (Demeter et al. 2007; Benetka et al. 2011; Nikolin et al. 2012; Billinis et al. 2013).

In parallel, there was a major, independent $\mathrm{CD}$ outbreak in free-ranging Apennine wolves (Canis lupus) in Italy. The identified virus belonged to the Arctic lineage, with a high genetic relatedness to strains from Italian dogs, suggesting that dogs were the likely source of infection (Di Sabatino et al. 2014).
Red foxes and badgers were affected by CDV in the same area, but the lineage was not confirmed. There was also CD emergence in wildlife in Germany independent of the epidemic wave in central Europe (Nikolin et al. 2012). Similarly, an apparently isolated outbreak, affecting mainly stone martens in Belgium, was suspected to be due to CDV spreading from endemic areas in central Europe toward naïve, west-European populations prior to the major epidemic wave (Tavernier et al. 2012). Finally, in 2011 a severe outbreak was reported in ferrets in the UK (Thomas 2012). Figure 6 shows the countries and species in which CDV was detected during this period.

Presently, CDV is of growing concern due to its propensity for host-switching and emergence in new species, including endangered wildlife; this poses challenges for disease control. The dynamics of CDV in 
natural ecosystems are highly complex, and spillover from dogs into multihost systems can result in development of a maintenance community (Viana et al. 2015). Reduced vaccination of domestic dogs, increased pet movement, and human encroachment into wildlife habitats pose serious risks for spread and re-emergence of CDV in free-ranging wildlife. Conversely, infected wild populations may increasingly be a source of infection for domestic animals and captive wild animals. Furthermore, outbreaks in nonhuman primates, and the clear ability of the virus to cross species barriers, have raised concern that CDV could become a threat to humans. Some viral proteins of CDV and of the closely related measles virus are interchangeable, and certain CDV strains have the potential to replicate in human epithelial cell lines. Therefore, CDV may have sufficient latent potential to adapt and cause disease in humans (Otsuki et al. 2013).

\section{Lagovirus infections in wild rabbits and hare, by Antonio Lavazza}

Rabbit hemorrhagic disease (RHD) and European brown hare syndrome (EBHS) are similar diseases caused by two related but phylogenetically distinct RNA viruses of the genus Lagovirus, family Caliciviridae. Both RHD and EBHS have a restricted host specificity, both naturally and experimentally (Lavazza et al. 1996); they were initially considered genus-specific, with RHD infecting wild and domestic European rabbits and EBHS mainly brown hares.

Rabbit hemorrhagic disease virus infections: There is worldwide occurrence for RHD, particularly where wild rabbits are common in Europe and Oceania. However, Lagovirus infections affect not only wildlife conservation and biodiversity but may also affect the health of farmed rabbits, causing economic losses. This is particularly evident in those European countries (Italy, France, Spain, Portugal, Belgium, Greece, Malta, Hungary) where rabbit farming is an active livestock production industry.

Only one serotype of rabbit hemorrhagic disease virus (RHDV) is known, including the main antigenic variant named RHDVa. However, pathogenic RHDV strains can be classified into three major phylogenetically distinct groups (Kerr et al. 2009) and at least six genogroups with a particular temporal distribution (Le Gall-Reculé et al. 2003). Moreover, the presence and circulation in Europe of different nonpathogenic RHDVlike viruses, similar to rabbit calicivirus (RCV) characterized in farmed rabbits 1996 in Italy and RCV-A1 in young wild Australian rabbits, were recently confirmed (Le Gall-Reculé et al. 2003; L. Capucci and P. Cavadini pers. obs.). These results indicate the existence of a gradient of cross-protection between circulating strains in Europe, from nonprotective to partially protective to fully protective strains, and highlight the extent of diversity within the genus Lagovirus.

In 2010, a new RHDV-related pathogenic virus (RHDV2) was detected in France, initially in wild rabbits and then in farmed rabbits vaccinated with RHDV vaccine (Le Gall-Reculé et al. 2013). The origin of RHDV2 is still under investigation, but preliminary results indicate it did not evolve from RHDV but is a new viral emergence from an unknown source (Le Gall-Reculé et al. 2013). The genomic and antigenic profiles of RHDV2 are different from RHDV to such an extent that it could be considered a distinct serotype. Therefore, the name RHDV2 seems more appropriate than the RHDVb used by some authors.

In the years following the initial outbreak in 2010, RHDV2 spread rapidly within Europe, causing significant losses in farmed and wild rabbits in France, Italy, Portugal, Spain, Germany, the UK, Malta, Norway, Sweden, Denmark, Switzerland, the Netherlands, Hungary, and Belgium. Outside Europe, RHDV2 is reported in Australia and Canada. The disease caused by RHDV2 does not show significant clinical, pathologic (Fig. 7), and epidemiologic differences from "classical" RHD but it has the capacity to infect young rabbits $10-15 \mathrm{~d}$ old. The mortality rates vary depending on viral strain, from $5-20 \%$ in strains identified in $2010-13$ up to $80 \%$ in more recent isolates (2014-15) (Capucci et al. 


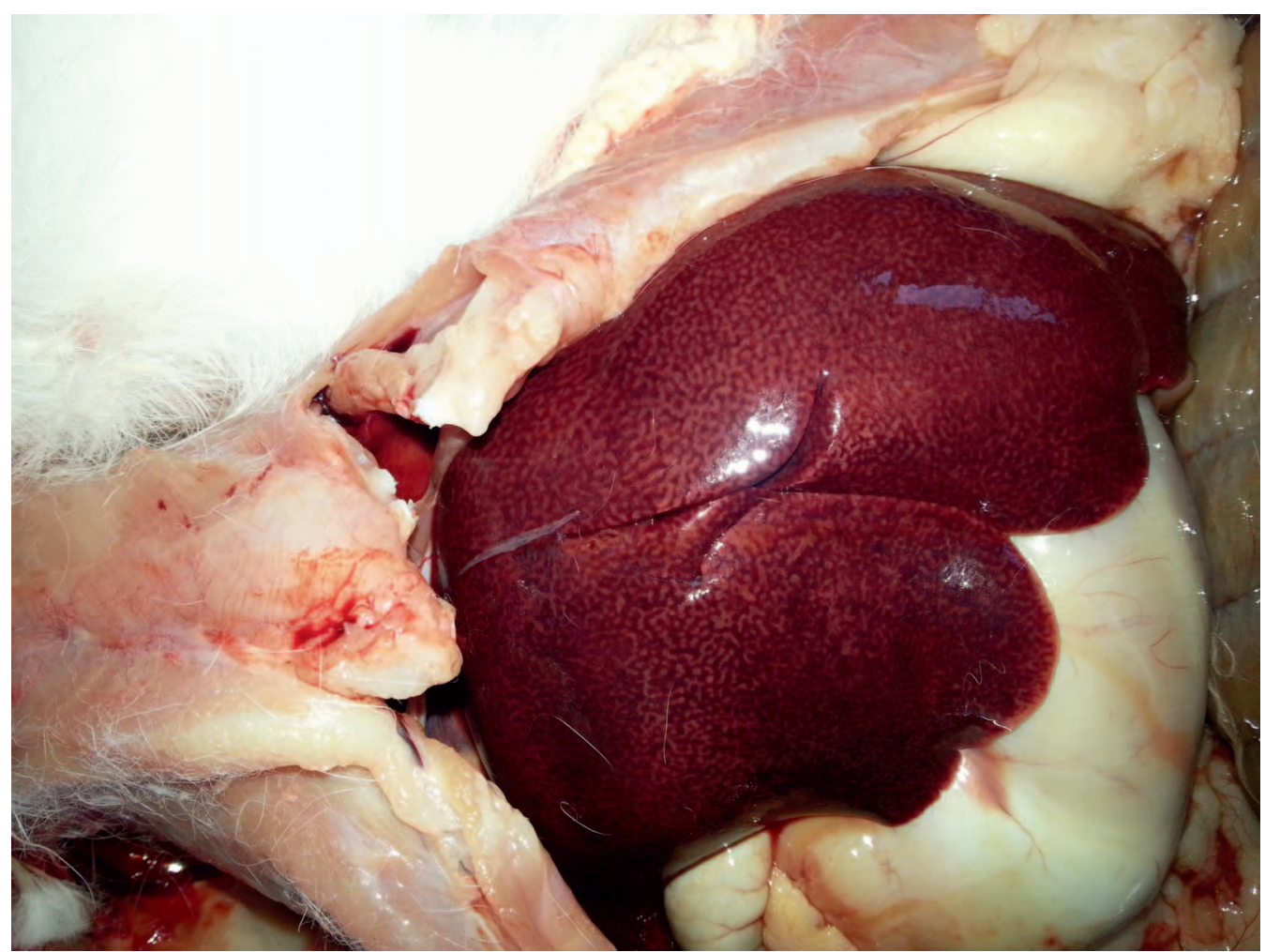

Figure 7. Liver degeneration and congestion with evident lobular pattern in a doe (Oryctolagus cuniculus, breed "Bianca Italiana") affected by acute rabbit hemorrhagic disease virus (photograph courtesy of Istituto Zooprofilattico Sperimentale della Lombardia e dell'Emilia Romagna's archive). Photograph taken at necropsy during an RHDV2 outbreak in Puglia, Foggia province in March 2013.

2017). Additionally, RHDV2 infects and causes EBHSV-like disease in three hare species: Cape hare (Lepus capensis subsp. mediterraneus) in Sardinia (Puggioni et al. 2013), Italian hare (Lepus corsicanus) in one case in Sicily (Camarda et al. 2014), and European brown hare in Spain and Italy (Velarde et al. 2016), France (Le Gall-Reculé et al. 2016), and Australia (Hall et al. 2016). These last findings suggest a species jump of lagoviruses between lagomorph genera, suggesting possible risk for different hare populations. Given these data, and the low immunity among wild rabbit populations (due to the poor cross-protection induced by "classical" RHDV), RHDV2 could pose a significant threat to wild rabbit populations and may result in a substantial future population decline.
European brown hare syndrome: Since the first description of EBHS in Sweden in the early 1980s (Gustafsson et al. 1989), its distribution has been restricted to Europe, affecting primarily the European brown hare as the main host species. European brown hare syndrome has been also reported with lower frequency in mountain hare and Italian hare but not in other European Lepus species such as L. granatensis and L. castroviejoi, both present mainly in the Iberian Peninsula and the Cape hare in Sardinia (Puggioni et al. 2013). In addition, field and experimental data recently demonstrated that the eastern cottontail (Sylvilagus floridanus) is susceptible to infection with European brown hare syndrome virus (EBHSV) (but not RHDV), occasionally causing EBHS-like disease (Lavazza et al. 2015). The eastern cottontail could therefore be considered a spillover or dead- 
end host for EBHSV unless new evidence shows an active role in the epidemiology of EBHSV (Lavazza et al. 2015).

One viral serotype of EBHSV is recognized but, in a study of 169 strains in France in 19892003, several genogroups were identified (Le Gall-Reculé et al. 2006). However, in contrast to RHDV, the distribution of EBHSVs suggests that the early viruses have not disappeared but have slowly evolved in their area of origin. A retrospective genetic and antigenic analysis of samples collected in Sweden from 1982-2008 revealed two lineages: Group A, which existed until 1989 when it apparently underwent extinction; and Group B, which emerged in the mid-1980s and from which the most recent strains have come (Lopes et al. 2014). However, EBHSV causes lower mortality than does RHD, and dramatic changes in structure and pathogenicity, as have been seen with RHDV2, have not been observed for EBHSV. Indeed, passive surveillance monitoring programs indicate a progressive decrease in the number of cases in wild hares in most European countries in recent years.

Chiari et al. (2014) found that population density influences virus maintenance in the hare population: antibody prevalence was 3.3 times higher in high-density areas $(>15$ hare/ $\mathrm{km}^{2}$ ). Because eradication of EBHS in wild populations is not feasible, the only way of minimizing the impact of EBHS and maintaining its incidence at low levels is a strategy that implies the maintenance of a high hare population density. In this situation, hare more easily and frequently become infected when they are young $(<2-3$ mo old; i.e., when they are able to develop an active and protective immunity without showing clinical signs or succumbing to disease). A progressive temporal decline in antibody prevalence and the detection of EBHSV was seen over $7 \mathrm{yr}$ (2006-13); therefore, there may be a higher risk of emergence of new EBHS epidemics in these now-naïve populations.

\section{Morbillivirus infections in aquatic mammals, by Thijs Kuiken}

Morbillivirus disease occurs sporadically in several species of seals and cetaceans in
European waters. Major epidemics occurred in the North Sea in 1988 and 2002, in the Mediterranean Sea in 1990-92 and 2006-08, and in the Caspian Sea in 2000 (Rijks et al. 2012). In 2011, van Elk et al. (2014) detected dolphin morbillivirus (DMV) in two whitebeaked dolphins (Lagenorhynchus albirostris) that stranded on the Dutch coast of the North Sea. As the stranding rate did not increase in the region, they concluded that DMV likely was not highly virulent for white-beaked dolphins.

In 2011, DMV caused an epidemic with high mortality in striped dolphins (Stenella coeruleoalba) on the Spanish (Rubio-Guerri et al. 2013) and Italian Mediterranean coasts (Di Guardo et al. 2013). Smaller numbers of bottlenose dolphins (Tursiops truncatus) and fin whales (Balaenoptera physalus) also stranded and were positive for DMV. In the first 3 mo of 2013, there was an unusually high stranding rate of (mainly) striped dolphins on the Italian coast and again DMV was detected in a high proportion (24 of 57) of carcasses tested (Casalone et al. 2014).

A different morbillivirus is an important pathogen in seals; after the last phocine distemper virus (PDV) epidemic in harbor seals (Phoca vitulina) in 2002 (Jensen et al. 2002), which killed about half of the North Sea population, the virus disappeared and the proportion of animals without anti-PDV antibodies increased to an estimated $89 \%$ by 2012 (Bodewes et al. 2013a). This suggests that reintroduction of PDV into the North Sea harbor seal population would result in another epidemic with similar infection and mortality rates.

In general, morbilliviruses do not appear to be maintained in aquatic mammal populations in European waters (Rijks et al. 2012). Dolphin morbillivirus can be highly pathogenic for striped dolphins and may negatively affect other cetacean species. For PDV, evidence suggests that these populations lose specific immunity with time, rendering them at risk of "virgin soil" epidemics, which can cause high mortality in a short time. 


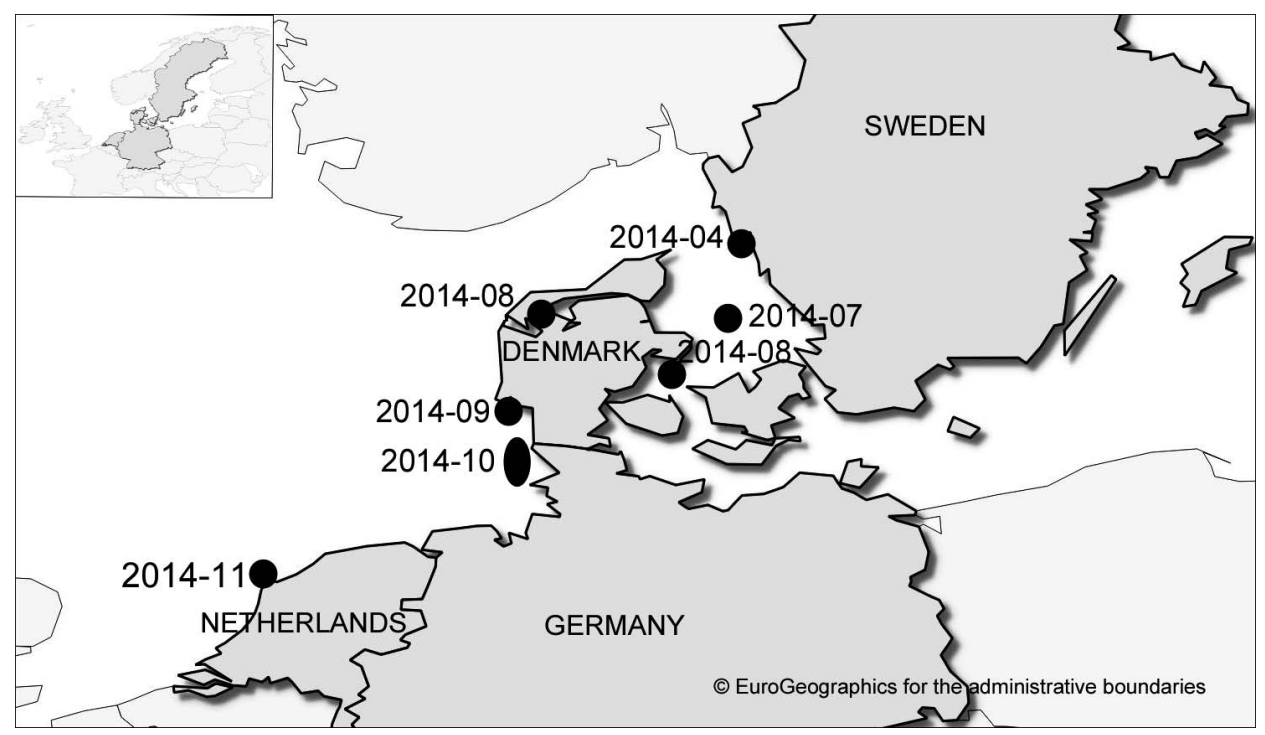

Figure 8. Timing and progression of the H10N7 avian influenza outbreak in harbor seals (Phoca vitulina) in northern Europe in 2014. The H10N7 avian influenza virus was first confirmed in a seal in Sweden in April 2014; it then spread along the coasts of Denmark, Germany, and the Netherlands (figure by Aleksija Neimanis).

\section{Seal influenza virus infections, by Aleksija Neimanis}

Wild waterbirds serve as the natural reservoirs for avian influenza A viruses (AIV) and, although sporadic transmission to marine mammals occurs, confirmed outbreaks of AIV-associated disease have been restricted to harbor seals in the USA (Fereidouni et al. 2016). A mass mortality event involving thousands of harbor seals began in March 2014 off the west coast of Sweden and spread to Denmark, Germany, and the Netherlands (Zohari et al. 2014; Bodewes et al. 2015a, 2016; Krog et al. 2015; Fig. 8). During that event, AIV was isolated from several dead harbor seals. The virus was characterized as subtype H10N7, most closely related to AIVs of Eurasian lineage circulating in wild and domestic birds (Zohari et al. 2014; Bodewes et al. 2015a; Krog et al. 2015). Infection targeted the respiratory tract and concurrent bacterial pneumonia was often seen. This was the first isolation of the H10 subtype from seals and the first documented AIV-associated epidemic in harbor seals in Europe.

In addition to potential impacts on seal populations (e.g., Bodewes et al. 2015a reported mortality of up to $12 \%$ of the
Schleswig-Holstein population), H10N7 infection of harbor seals may have public health significance. Although the zoonotic potential of H10N7 has not been assessed, productive infection was demonstrated experimentally in ferrets (Mustela putori furo; van den Brand et al. 2016). Ferrets often are used in animal models for influenza in humans because of their similar susceptibility to infection and disease from influenza viruses and the similarities in histology, anatomy, and pattern of virus attachment between ferret and human respiratory tracts (van den Brand et al. 2014). An AIV strain previously isolated during a harbor seal epidemic (H7N7) caused conjunctivitis in humans, and another strain (H3N8) from harbor seals had adaptations that are known, in other AIVs, to increase transmissibility and virulence to mammals (Fereidouni et al. 2016). Furthermore, certain H10 strains cause severe disease in some mammalian species without prior adaptation in poultry (Zohari et al. 2014). Finally, harbor seals in California had antibodies to a human pandemic influenza A virus, suggesting harbor seals could be coinfected with avian- and human-origin influenza A viruses and might serve as mixing hosts (Boyce et al. 2013). The 
H10N7 virus was circulating in European harbor seals for at least $10 \mathrm{mo}$, and molecular analyses identified amino acid changes not present in H10 viruses from Eurasian birds, which suggests viral adaptation to the new mammalian host (Bodewes et al. 2016).

Given the spread of H10N7 through harbor seal colonies in the Kattegat, North, and Wadden Seas, AIV could infect all harbor seal colonies in Northern Europe. Antibodies to H10N7 were detected in grey seals (Halichoerus grypus) from Dutch waters (Bodewes et al. 2015b), indicating that other sympatric marine mammal species may play a role in the epidemiology. Finally, infection of European marine mammals with novel AIV strains can be expected to occur again, and surveillance for AIV in marine mammals, coupled with further investigation of viral adaptation, pathology, epidemiology, and zoonotic potential of H10N7, are warranted.

\section{DISCUSSION}

We selected 25 pathogens affecting European wild animals that have undergone significant epidemiologic changes during 2010-16. These changes have already had an impact on the health of wildlife, livestock, and humans (either singly or, frequently, in combination; Table 2), or the changes maydue to their recently emerging nature-have an impact on any or all of these populations in the future. Due to changes in their epidemiology, the diseases associated with these pathogens can be considered EIDs in Europe, and specifically EIDs in which wildlife has had or may have a central role.

The epidemiologic changes in these diseases usually consisted of an increase in number of susceptible host species, an expansion of geographic range, or involved the emergence of new pathogens or new variants of existing pathogens (Table 2). However, for some of the listed pathogens (e.g., bat lyssaviruses, hepatoviruses, filoviruses, and hantaviruses), emergence was likely also related to increased awareness of them and improved sensitivity of methods for their detection.
The number of recognized pathogens that can be transmitted between wildlife and domestic animals is increasing, and the pathogens may pose significant threats to either or both populations. The predicted increase in livestock production to meet the growing demand for meat (Bruinsma 2003) is likely to add to the risk of pathogen exchange between livestock and wild animal populations. In many cases, wild ungulate populations in Europe have recovered, grown, and expanded so that they have increasing contact with livestock, further increasing the risk of pathogen exchange between the two populations (Martin et al. 2011). The emergence and spread of ASF in Europe highlights the importance of international collaboration in surveillance to identify emerging threats and to improving our understanding of the role of wildlife in the epidemiology of EIDs. African swine fever was detected for the first time in Eastern Europe in recent years and spread back into domestic pigs after being introduced into free-ranging wild boar populations. The re-emergence and spread of HPAI (H5N1 and H5N8) in Europe is another example demonstrating the links between wildlife and domestic animal health and the importance of ongoing disease surveillance in both populations. Transmission of $\mathrm{H} 5 \mathrm{N1}$ and $\mathrm{H} 5 \mathrm{~N} 8$ between wild birds and domestic poultry has been clearly demonstrated, and there is continued potential for the spread and movement of these viruses from migratory wild birds to poultry farms.

Climate change is often implicated as an important factor in EIDs in Europe, and we note the northerly spread in Europe of seven (28\%) of the pathogens discussed in this review: CCHV, Leishmania, WNV, BTV, SBV, Francisella tularensis, and Echinococcus multilocularis. The first five agents are arthropod vector-borne whila $\rightarrow$. tularensis may be vector-borne. However, it is difficult to provide scientific evidence for causal links because there are many complex and interrelated factors involved, long-term data on most diseases are lacking, and climatic conditions cannot be experimentally reproduced. Nonetheless, vector-borne diseases, which are 
widespread across all latitudes in Europe, offer examples of changes in their epidemiology in association with climatic changes (Semenza and Menne 2009). Closer inspection, for example seen in a model for WNV, indicated that mild winters, dry summers and springs (with heat waves early in the season), and wet autumns were favorable for the reproduction of mosquitoes (e.g., Culex pipiens) dwelling in cities, and this tended to concentrate vectors around water sources in close proximity to their avian hosts, leading to multiplication of the virus. The WNV outbreaks in Romania and Israel, which were associated with a heat wave early in the summer, provided evidence to support the model (Epstein 2001). Another example is seen with leishmaniasis-temperature influences the biting activity rates of the sandfly vector as well as the diapause and maturation of $L$. infantum in the sandfly. The distribution of sandflies in Europe has shifted northward from south of latitude $45^{\circ} \mathrm{N}$ to $49^{\circ} \mathrm{N}$, and recently they have been reported in northern Germany (Perrotey et al. 2005). Imported cases of leishmaniasis in dogs are frequent in central and northern Europe. If climatic conditions make transmission possible in northern latitudes where sandflies have expanded their range, these cases can act as further sources of infections, allowing the development of new endemic foci (Semenza and Menne 2009). Both WNV and Leishman$i a$ are zoonotic and so will pose a previously unrecognized health risk to human populations in these regions previously unaffected; thus, a better understanding of the epidemiology of these pathogens, their vectors, and the trend in vector movements are essential for mitigation of the risks to human and animal health. There has been recrudescence of diseases caused by pathogens that, in the years prior to the period of this review, had apparently been relatively quiescent or at least undetected. Studies indicate a spread in the geographic range in which CDV has been detected and, of greater concern, its emergence in several new host species including rodents and a threatened felid species the Iberian lynx) (Meli et al. 2010; Trebbien et al.
2014). In recent years, a new RHD virus serotype, RHDV2, has rapidly spread across most of Europe (to 14 countries during the period covered by this review) and caused epidemics in wild and farmed rabbits (Capucci et al. 2017). In most areas, RHDV2 appears to have efficiently and rapidly replaced RHDV (the old, or 'classical' RHDV) during the 7-yr period assessed in this review. Exposure to RHDV, which has been prevalent in wild rabbit populations in Europe since its first occurrence there in 1986, confers only partial immunity to infection by the new virus; thus, there have been new outbreaks of mortality. Of concern from an EID point of view is that the new serotype, RVHD2, causes disease and mortality in hares as well as in rabbits (Le Gall-Reculé et al. 2016); thus, for the first time, extending the host species range beyond the European rabbit. This underscores the importance of continued vigilance, even for pathogens believed to be well understood, controlled, and quiescent.

Several pathogens are having a profound impact on biodiversity and on species of conservation importance in Europe. Amphibian ranaviruses and B. salamandrivorans pose threats to anuran and salamander populations, respectively, creating the risk of extirpation of populations over large regions of Europe. The severe epidemic of Bsal in Europe is likely the result of the global trade in amphibians, which introduced Bsal into naïve amphibian populations (Martel et al. 2013). Wildlife populations globally may experience numerous stressors including climate change, reduced or fragmented habitat, reduced genetic variability, diminished food supplies, hunting pressure, and increased human encroachment on the landscape; all of these can weaken resistance and increase susceptibility to disease. These stressors are each of importance for European wildlife; however, incursion of new pathogens also appears to be a significant driver of EIDs in Europe. Of the 25 EID threats in Table 2, 24\% are from incursions of pathogens from other continents, including CCHV, filoviruses, WNV, ASFV, CWD prions, and Bsal. It could also be argued that highly pathogenic avian influenza virus 
(HPAIV) came from the Arctic and should be included in this list; regardless, there is clear evidence that Europe is at risk from incursion of new wildlife-related pathogens from other continents.

The information presented herein highlights the importance of developing systematic, integrated, regional, continental, and global wildlife disease surveillance programs that are linked to domestic animal and human health surveillance as part of a One-Health approach that recognizes and incorporates the threats to biodiversity and wildlife conservation. A consistent theme that emerged from this review is the importance of ongoing disease surveillance in wildlife; essential reasons for this surveillance were also listed in the Introduction. While our intent with this review was to provide an update on changes in each pathogen over a 7-yr span, changes were evident across a wide range of pathogens over this period, suggesting that drivers of change in pathogen epidemiology, whether or not they have yet been identified, are active in Europe. There is a real and larger global perspective in this regard. European homegrown, wildlife-related pathogens are 'ready for export' to other continents (e.g., lagoviruses, SBV, E. multilocularis, L. infantum, and $M$. bovis) and, increasingly, there are also incursions of pathogens into Europe from the four points of the compass: Africa to the south (ASFV, CCHFV, filoviruses, WNV); Asia to the east (AIV, Bsal); the Arctic to the north (AIV in birds and seals, morbilliviruses, CDV); and the Americas to the west (CWD prions). Europe is a crossroads for global, wildliferelated diseases, and the movement of the causative pathogens into and across the highly developed and human-dominated continent may be surprising. Pathogens may move spatially through populations; however, the mobility of wild species carrying pathogens in Europe is also noteworthy, with migrating insects (vectors), birds, and marine mammals, and large land-based vertebrates that can travel hundreds of kilometers (e.g., wolves, foxes, raccoon dogs). If Europeans deem it important to monitor the health of their natural environments, then there is a con- comitant requirement to monitor the pathogens in the wildlife inhabiting those landscapes and to assess how these are changing over time. In our increasingly linked world, the movement and spread of pathogens between species and across geographic regions requires integrated monitoring and vigilance at regional, continental, and global scales. This review highlights the importance of the surveillance of wildlife diseases in Europe at a level that compliments the current investment in surveillance of domestic animal and human health. Moreover, given disease transmission among human, domestic animal, and wildlife populations, it is essential that health surveillance of these three populations be well integrated. In line with the One-Health principle, development of integrated surveillance network would improve preparedness for future threats to the health of wildlife, domestic animals, and humans.

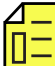

\section{ACKNOWLEDGMENTS}

We ${ }_{\lambda}$ acknowledge Edouard Reveillaud: French agency for food, environmental and occupational health and safety (ANSES), and Becki Lawson: Institute of Zoology, London, F.R.F. was funded by the Spanish Ministry for the Economy, Industry and Competitiveness (MINECO) through the 'Ramón y Cajal' program. Thanks to the Wildlife Disease Association Small Grants Program for covering the costs for publication of this manuscript $\wedge$

\section{LITERATURE CITED}

ADNS (Animal Disease Notification System). 2017a. https://ec.europa.eu/food/animals/ animal-diseases/not-system_en. Accessed June 2018. ADNS (Animal Disease Notification System). 2017b. https://ec.europa.ew/food/animals animal-diseases/not-system_en. Accessed June 2018.

Aime B, Lequen L, Balageas A, Haddad N, Maugein J. 2012. M. bovis and M. caprae infections in Aquitaine: A clinico-epidemiologic study of 15 patients. Pathol Biol (Paris) 60:156-159.

Alexander DJ. 2007. An overview of the epidemiology of avian influenza. Vaccine 25:5637-5644.

Amman BR, Carroll SA, Reed ZD, Sealy TK, Balinandi S, Swanepoel R, Kemp A, Erickson BR, Comer JA, Campbell S, et al. 2012. Seasonal pulses of Marburg virus circulation in juvenile Rousettus aegyptiacus bats coincide with periods of increased risk of human infection. PLoS Pathog 8:e1002877. 
Andreoletti O, Berkvens D, Ducrot C, Gavier-Widen D, Griffin J, Hope J, Vanopdenbosch E. 2010. Scientific opinion on the results of the EU survey for chronic wasting disease (CWD) in cervids. EFSA Journal 8: 1861.

APHAEA. 2016. Harmonised approaches in monitoring wildlife population health and ecology and abundance. https:/www.aphaea.eu/content/brief-projectdescription-and-aims. Accessed June 2018.

Arce A, Estirado A, Ordobas M, Sevilla S, García N, Moratilla L, De La Fuente S, Martínez A, Pérez A, Aránguez E. 2013. Re-emergence of leishmaniasis in Spain: Community outbreak in Madrid, Spain, 2009 to 2012. Euro Surveill 18:20546.

Arechiga Ceballos N, Vazquez Moron S, Berciano JM, Nicolas O, Aznar Lopez C, Juste J, Rodriguez Nevado C, Aguilar Setien A, Echevarria JE. 2013. Novel lyssavirus in bat, Spain. Emerg Infect Dis 19:793-795.

ASF-STOP COST Action. 2016. ASF-STOP COST Action. https://www.asf-stop.com/. Accessed June 2018.

Avsic Zupanc T, Korva M, Markotic A. 2014. HFRS and hantaviruses in the Balkans/South-East Europe. Virus Res 187:27-33.

Badrane H, Tordo N. 2001. Host switching in lyssavirus history from the Chiroptera to the Carnivora orders. J Virol 75:8096-8104.

Bakonyi T, Ferenczi E, Erdélyi K, Kutasi O, Csörgő T, Seidel B, Weissenböck H, Brugger K, Bán E, Nowotny N. 2013. Explosive spread of a neuroinvasive lineage 2 West Nile virus in Central Europe, 2008/2009. Vet Microbio 165:61-70.

Balá V, Vojar J, Civi P, Rozínek R. 2014. Chytridiomycosis risk among Central European amphibians based on surveillance data. Dis Aquat Org 112:1-8.

Barlow A, Gottstein B, Müller N. 2011. Echinococcus multilocularis in an imported captive European beaver (Castor fiber) in Great Britain. Vet Rec 169: 339.

Barun A, Simberloff D, Budinski I. 2010. Impact of the small Indian mongoose on native amphibians and reptiles of the Adriatic islands, Croatia. Anim Conserv 13:549-555.

Benestad SL, Mitchell G, Simmons M, Ytrehus B, Vikøren T. 2016. First case of chronic wasting disease in Europe in a Norwegian free-ranging reindeer. Vet Res 47:88.

Benetka V, Leschnik M, Affenzeller N, Möstl K. 2011. Phylogenetic analysis of Austrian canine distemper virus strains from clinical samples from dogs and wild carnivores. Vet Rec 168:377.

Biglino A, Bolla C, Concialdi E, Trisciuoglio A, Romano A, Ferroglio E. 2010. Asymptomatic Leishmania infantum infection in an area of northwestern Italy (Piedmont region) where such infections are traditionally nonendemic. J Clin Microbiol 48:131-136.

Billinis C, Athanasiou L, Valiakos G, Mamuris Z, Birtsas P, Spyrou V. 2013. Phylogenetic analysis of canine distemper viruses from red foxes, Greece. Vet Rec 173:194.
Bodewes R, Bestebroer TM, van der Vries E, Verhagen JH, Herfst S, Koopmans MP, Fouchier RAM, Pfankuche VM, Wohlsein P, Siebert U, et al. 2015a. Avian influenza $\mathrm{A}(\mathrm{H} 10 \mathrm{~N} 7)$ virus-associated mass deaths among harbor seals. Emerg Infect Dis 21: $720-722$.

Bodewes R, Garcia AR, Brasseur SM, Conteras GJS, Van De Bildt MW, Koopmans MP, Osterhaus AD, Kuiken T. 2015b. Seroprevalence of antibodies against seal influenza A (H10N7) virus in harbor seals and gray seals from the Netherlands. PloS One 10:e0144899.

Bodewes R, Morick D, van de Bildt MWG, Osinga N, Garcia AR, Contreras GJS, Smits SL, Reperant LAP, Kuiken T, Osterhaus ADME. 2013a. Prevalence of phocine distemper virus specific antibodies: Bracing for the next seal epizootic in north-western Europe. Emerg Microbes Infec 2:e2.

Bodewes R, van der Giessen J, Haagmans BL, Osterhaus AD, Smits SL. 2013b. Identification of multiple novel viruses, including a parvovirus and a hepevirus, in feces of red foxes. J Virol 87:7758-7764.

Bodewes R, Zohari S, Krog JS, Hall MD, Harder TC, Bestebroer TM, van de Bildt MW, Spronken MI, Larsen LE, Siebert U. 2016. Spatiotemporal analysis of the genetic diversity of seal influenza A (H10N7) virus, northwestern Europe. J Virol 90:4269-4277.

Bosch J, Sanchez-Tomé E, Fernández-Loras A, Oliver JA, Fisher MC, Garner TW. 2015. Successful elimination of a lethal wildlife infectious disease in nature. Biol letters 11:20150874.

Boyce WM, Mena I, Yochem PK, Gulland FM, GarcíaSastre A, Moreno N, Perez DR, Gonzalez-Reiche AS, Stewart BS. 2013. Influenza A (H1N1) pdm09 virus infection in marine mammals in California. Emerg Microbes Infec 2:e40.

Botvinkin AD, Poleschuk EM, Kuzmin IV, Borisova TI, Gazaryan SV, Yager P, Rupprecht CE. 2003. Novel lyssaviruses isolated from bats in Russia. Emerg Infect Dis 9:1623-1625.

Bruinsma J, editor.2003. World agriculture: Towards 2015/2030: An FAO perspective. Earthscan, London, UK, 432 pp.

Cadar D, Lühken R, van der Jeugd H, Garigliany M, Ziegler U, Keller M, Lahoreau J, Lachmann L, Becker N, Kik M. 2017. Widespread activity of multiple lineages of Usutu virus, Western Europe, 2016. Eurosurveillance 22: pii:30452.

Camarda A, Pugliese N, Cavadini P, Circella E, Capucci L, Caroli A, Legretto M, Mallia E, Lavazza A. 2014. Detection of the new emerging rabbit haemorrhagic disease type 2 virus (RHDV2) in Sicily from rabbit (Oryctolagus cuniculus) and Italian hare (Lepus corsicanus). Res Vet Sci 97:642-645.

Capucci L, Cavadini P, Schiavitto M, Lombardi G, Lavazza A. 2017. Increased pathogenicity in rabbit haemorrhagic disease virus type 2 (RHDV2). Vet Rec 180:426.

Casalone C, Mazzariol S, Pautasso A, Di Guardo G, Di Nocera F, Lucifora G, Ligios C, Franco A, Fichi G, 
Cocumelli C, et al. 2014. Cetacean strandings in Italy: An unusual mortality event along the Tyrrhenian Sea coast in 2013. Dis Aquat Organ 109:81-86.

Chiari M, Ferrari N, Giardiello D, Avisani D, Zanoni M, Alborali GL, Lanfranchi P, Guberti V, Lorenzo C, Antonio L. 2014. Temporal dynamics of European brown hare syndrome infection in Northern Italian brown hares (Lepus europaeus). Eur J Wildlife Res 60:891-896

Chiari M, Zanoni M, Tagliabue S, Lavazza A, Alborali LG. 2013. Salmonella serotypes in wild boars (Sus scrofa) hunted in northern Italy. Acta Vet Scand 55:42.

Ciliberti A, Gavier-Widen D, Yon L, Hutchings MR, Artois M. 2015. Prioritisation of wildlife pathogens to be targeted in European surveillance programmes: Expert-based risk analysis focus on ruminants. Prev Vet Med 118:271-284.

Comte S, Raton V, Raoul F, Hegglin D, Giraudoux P, Deplazes P, Favier S, Gottschek D, Umhang G, Boué F. 2013. Fox baiting against Echinococcus multilocularis: Contrasted achievements among two medium size cities. Prev Vet Med 111:147-155.

Conraths FJ, Deplazes P. 2015. Echinococcus multilocularis: Epidemiology, surveillance and state-ofthe-art diagnostics from a veterinary public health perspective. Vet Parasitol 213:149-161.

Costard S, Mur L, Lubroth J, Sanchez-Vizcaino J, Pfeiffer D. 2013. Epidemiology of African swine fever virus. Virus Res 173:191-197.

Cunningham A, Langton T, Bennett P, Lewin J, Drury S, Gough R, Macgregor S. 1996. Pathological and microbiological findings from incidents of unusual mortality of the common frog (Rana temporaria). Philos Trans R Soc Lond B 351:1539-1557.

Daszak P, Cunningham AA, Hyatt AD. 2000. Emerging infectious diseases of wildlife-Threats to biodiversity and human health. Science 287:443-449.

Demeter Z, Lakatos B, Palade EA, Kozma T, Forgách P, Rusvai M. 2007. Genetic diversity of Hungarian canine distemper virus strains. Vet microbig $122: 258$ 269.

Di Guardo G, Di Francesco CE, Eleni C, Cocumelli C, Scholl F, Casalone C, Peletto S, Mignone W, Tittarelli C, Di Nocera F, et al. 2013. Morbillivirus infection in cetaceans stranded along the Italian coastline: Pathological, immunohistochemical and biomolecular findings. Res Vet Sci 94:132-137.

Di Sabatino D, Lorusso A, Di Francesco CE, Gentile L, Di Pirro V, Bellacicco AL, Giovannini A, Di Francesco G, Marruchella G, Marsilio F. 2014. Arctic lineage-canine distemper virus as a cause of death in Apennine wolves (Canis lupus) in Italy. PloS One 9: e82356.

Duffus AL, Nichols RA, Garner TW. 2014. Experimental evidence in support of single host maintenance of a multihost pathogen. Ecosphere 5:1-11.

Duffus AL, Waltzek TB, Stöhr AC, Allender MC, Gotesman M, Whittington RJ, Hick P, Hines MK, Marschang RE. 2015. Distribution and host range of ranaviruses. In: Ranaviruses, Gray M, Chinchar V, editors. Springer, New York, New York, pp. 9-57.

Dupinay T, Pounder KC, Ayral F, Laaberki MH, Marston DA, Lacote S, Rey C, Barbet F, Voller K, Nazaret N, et al. 2014. Detection and genetic characterization of Seoul virus from commensal brown rats in France. Virol J 11:32

Durán-Martínez M, Ferroglio E, Acevedo P, Trisciuoglio A, Zanet S, Gortázar C, Ruiz-Fons F. 2013. Leishmania infantum (Trypanosomatida: Trypanosomatidae) phlebotomine sand fly vectors in continental mediterranean Spain. Environ Entomol 42:11571165

Eisenberg T, Hamann H-P, Kaim U, Schlez K, Seeger H, Schauerte N, Melzer F, Tomaso H, Scholz HC, Koylass MS. 2012. Isolation of potentially novel Brucella spp. from frogs. Appl Environ Microb 78: 3753-3755.

Epstein PR. 2001. Climate change and emerging infectious diseases. Microbes Infect 3:747-754.

Estrada-Peña A, Jameson L, Medlock J, Vatansever Z Tishkova F. 2012a. Unraveling the ecological complexities of tick-associated Crimean-Congo hemorrhagic fever virus transmission: A gap analysis for the western Palearctic. Vector-Borne Zoonotic Dis 12 743-752.

Estrada-Peña A, Palomar AM, Santibáñez P, Sánchez N, Habela MA, Portillo A, Romero L, Oteo JA. 2012b. Crimean-Congo hemorrhagic fever virus in ticks, southwestern Europe, 2010. Emerg Infect Dis 18: 179-180.

Estrada-Peña A, Ruiz-Fons F, Acevedo P, Gortazar C, la Fuente J. 2013. Factors driving the circulation and possible expansion of Crimean-Congo haemorrhagic fever virus in the western Palearctic. J Appl Microbiol 114:278-286.

European Centre for Disease Prevention and Control (ECDC). 2017. Brucellosis: Annual epidemiological report. https://ecdc.europa.eu/sites/portal/files/ documents/Brucellosis-Annual\%20epidemiological\% 20report_1_0.pdf. Accessed June 2018.

European Commission. 2015. WILDTECH Report Summary. https://www.cordis.europa.eu/result/ren/ 159413_en.html. Accessed June 2018.

European Commission. 2016. Facts and figures on organic agriculture in the European Union. DG Agriculture and Rural Development. 45 pp. http://ec. europa.eu/agriculture/rica/pdf/Organic_2016_web_ new.pdf. Accessed July 2018.

European Commission. 2017. Animal Diseases: Control Measures. https://ec.europa.eu/food/animals/ animal-diseases/control-measures_en. Accessed June 2018

European Wildlife Disease Association (EWDA). 2016. EWDA Google Group. http://ewda.org/ewdanetwork/ewda-google-group/. Accessed March 2018.

Fereidouni S, Munoz O, Von Dobschuetz S, De Nardi M. 2016. Influenza virus infection of marine mammals Ecohealth 13:161-170. 
Fernandez-Pacheco P, Fernandez-Pinero J, Aguero M, Jimenez-Clavero A. 2008. Bluetongue virus serotype 1 in wild mouflons in Spain. Vet Rec 162:659-660.

Ferroglio E, Maroli M, Gastaldo S, Mignone W, Rossi L. 2005. Canine leishmaniasis, Italy. Emerg Infect Dis 11:1618-1620.

Ferroglio E, Poggi M, Trisciuoglio A. 2008. Evaluation of $65 \%$ permethrin spot-on and deltamethrin-impregnated collars for canine Leishmania infantum infection prevention. Zoonoses Public Health 55:145-148.

Fijan N, Matasin Z, Petrinec Z, Valpotic I, Zwillenberg L. 1991. Isolation of an iridovirus-like agent from the green frog (Rana esculenta L.). Veterinarski Arhiv 61: $151-158$.

Fink M, Schleicher C, Gonano M, Prodinger WM, Pacciarini M, Glawischnig W, Ryser-Degiorgis M-P, Walzer C, Stalder GL, Lombardo D. 2015. Red deer as maintenance host for bovine tuberculosis, Alpine region. Emerg Infect Dis 21:464-467.

Fooks A, Brookes S, Johnson N, McElhinney L, Hutson A. 2003. European bat lyssaviruses: An emerging zoonosis. Epidemiol Infect 131:1029-1039.

Fooks AR, Banyard AC, Horton DL, Johnson N, McElhinney LM, Jackson AC. 2014. Current status of rabies and prospects for elimination. Lancet 384: 1389-1399.

Fretin D, Mori M, Czaplicki G, Quinet C, Maquet B, Godfroid J, Saegerman C. 2013. Unexpected Brucella suis biovar 2 infection in a dairy cow, Belgium. Emerg Infect Dis 19:2053-2054.

Freuling CM, Hampson K, Selhorst T, Schroder R, Meslin FX, Mettenleiter TC, Muller T. 2013. The elimination of fox rabies from Europe: Determinants of success and lessons for the future. Philos Trans $R$ Soc Lond B Biol Sci 368:20120142.

Freuling CM, Vos A, Johnson N, Kaipf I, Denzinger A, Neubert L, Mansfield KL, Hicks DJ, Nunez A, Tordo N, et al. 2009. Experimental infection of serotine bats (Eptesicus serotinus) with European bat lyssavirus type 1a (EBLV-1a). J Gen Virol 90:2493-2502.

Gaffuri A, Holmes JP. 2012. Salmonella infections. In Infectious diseases of wild mammals and birds in Europe, Gavier-Widen D, Duff JP, Meredith A, editors. Wiley-Blackwell, Oxford, UK, pp. 386-397.

Gallardo C, Fernández-Pinero J, Pelayo V, Gazaev I, Markowska-Daniel I, Pridotkas G, Nieto R, Fernández-Pacheco P, Bokhan S, Nevolko O, et al. 2014. Genetic variation among African swine fever genotype II viruses, eastern and central Europe. Emerg Infect Dis 20:1544-1547.

Gavier-Widen D. 2012. Prion infections. In: Infectious diseases of wild mammals and birds in Europe, Gavier-Widen D, Duff JP, Meredith A, editors. Wiley-Blackwell, Oxford, UK, pp. 489-496.

Gavier-Widen D, Cooke M, Gallagher J, Chambers M, Gortázar C. 2009. A review of infection of wildlife hosts with Mycobacterium bovis and the diagnostic difficulties of the 'no visible lesion' presentation. New Zeal Vet J 57:122-131.
Gavier-Widén D, Gortázar C, Ståhl K, Neimanis AS, Rossi S, Hård av Segerstad C, Kuiken T. 2015. African swine fever in wild boar in Europe: A notable challenge. Vet Rec 176:199-200.

Gilbert M, Miquelle DG, Goodrich JM, Reeve R, Cleaveland S, Matthews L, Joly DO. 2014. Estimating the potential impact of canine distemper virus on the Amur tiger population (Panthera tigris altaica) in Russia. Plos One 9:e110811.

Godfroid J, Scholz H, Barbier T, Nicolas C, Wattiau P, Fretin D, Whatmore A, Cloeckaert A, Blasco J, Moriyon I. 2011. Brucellosis at the animal/ecosystem/ human interface at the beginning of the 21st Century. Prev Vet Med 102:118-131.

González-Barrio D, Maio E, Vieira-Pinto M, Ruiz-Fons F. 2015. European rabbits as reservoir for Coxiella burnetii. Emerg Infect Dis 21:1055-1058.

Gottstein B, Stojkovic M, Vuitton DA, Millon L, Marcinkute A, Deplazes P. 2015. Threat of alveolar echinococcosis to public health-A challenge for Europe. Trends Parasitol 31:407-412.

Gray MJ, Miller DL, Hoverman JT. 2009. Ecology and pathology of amphibian ranaviruses. Dis Aquat Org 87:243-266.

Gustafsson K, Svensson T, Uggla A. 1989. Studies on an idiopathic syndrome in the brown hare (Lepus europaeus P.) and mountain hare (Lepus timidus L.) in Sweden, with special reference to hepatic lesions. Zentralbl Veterinarmed A 36:631-637.

Hall RN, Peacock DE, Kovaliski J, Mahar JE, Mourant R, Piper M, Strive T. 2016. Detection of RHDV2 in European brown hares (Lepus europaeus) in Australia. Vet Rec 180:121.

Hauer A, De Cruz K, Cochard T, Godreuil S, Karoui C, Henault S, Bulach T, Bañuls A-L, Biet F, Boschiroli ML. 2015. Genetic evolution of Mycobacterium bovis causing tuberculosis in livestock and wildlife in France since 1978. PLoS One 10:e117103.

Hernández-Triana LM, Jeffries CL, Mansfield KL, Carnell G, Fooks AR, Johnson N. 2014. Emergence of West Nile virus lineage 2 in Europe: A review on the introduction and spread of a mosquito-borne disease. Front Pub Health 2:271.

Hestvik G, Warns-Petit E, Smith LA, Fox NJ, Uhlhorn H, Artois M, Hannant D, Hutchings MR, Mattsson R, Yon L, et al. 2015. The status of tularemia in Europe in a One-Health context: A review. Epidemiol Infect 143:2137-2160.

Horton DL, Banyard AC, Marston DA, Wise E, Selden D, Nunez A, Hicks D, Lembo T, Cleaveland S, Peel AJ, et al. 2014. Antigenic and genetic characterization of a divergent African virus, Ikoma lyssavirus. J Gen Virol 95:1025-1032.

Horton DL, McElhinney LM, Freuling CM, Marston DA, Banyard AC, Goharrriz H, Wise E, Breed AC, Saturday G, Kolodziejek J, et al. 2015. Complex epidemiology of a zoonotic disease in a culturally diverse region: Phylogeography of rabies virus in the Middle East. PLoS Negl Trop Dis 9:e0003569. 
Horton R, Wu G, Speed K, Kidd S, Davies R, Coldham N, Duff J. 2013. Wild birds carry similar Salmonella enterica serovar Typhimurium strains to those found in domestic animals and livestock. Res Vet Sci 95:4548.

Huang F, Sun Z, Emerson S, Purcell R, Shivaprasad H, Pierson F, Toth T, Meng X. 2004. Determination and analysis of the complete genomic sequence of avian hepatitis E virus (avian HEV) and attempts to infect rhesus monkeys with avian HEV. J Gen Virol 85: 1609-1618.

International Committee on Taxonomy of Viruses (ICTV). 2014. Virus taxonomy: 2014 release. http://www. ictvonline.org/virusTaxonomy.asp. Accessed February 2016.

Izopet J, Dubois M, Bertagnoli S, Lhomme S, Marchandeau S, Boucher S, Kamar N, Abravanel F, Guérin J-L. 2012. Hepatitis E virus strains in rabbits and evidence of a closely related strain in humans, France. Emerg Infect Dis 18:1274-1281.

Jensen T, van de Bildt M, Dietz HH, Andersen TH, Hammer AS, Kuiken T, Osterhaus A. 2002. Another phocine distemper outbreak in Europe. Science 297: 209.

Johne R, Dremsek P, Reetz J, Heckel G, Hess M, Ulrich RG. 2014. Hepeviridae: An expanding family of vertebrate viruses. Infect Genet Evol 27:212-229.

Johnson N, Fooks AR, Valtchovski R, Muller T. 2007. Evidence for trans-border movement of rabies by wildlife reservoirs between countries in the Balkan Peninsula. Vet Microbiol 120:71-76.

Johnson N, Vos A, Freuling C, Tordo N, Fooks A, Müller T. 2010. Human rabies due to lyssavirus infection of bat origin. Vet Microbio 142:151-159.

Johnson N, Vos A, Neubert L, Freuling C, Mansfield KL, Kaipf I, Denzinger A, Hicks D, Nunez A, Franka R, et al. 2008. Experimental study of European bat lyssavirus type- 2 infection in Daubenton's bats (Myotis daubentonii). J Gen Virol 89:2662-2672.

Jones KE, Patel NG, Levy MA, Storeygard A, Balk D, Gittleman JL, Daszak P. 2008. Global trends in emerging infectious diseases. Nature 451:990-993.

Jonsson CB, Figueiredo LTM, Vapalahti O. 2010. A global perspective on hantavirus ecology, epidemiology, and disease. Clin Microbiol Rev 23:412-441.

Kerr PJ, Kitchen A, Holmes EC. 2009. Origin and phylodynamics of rabbit hemorrhagic disease virus. $J$ Virol 83:12129-12138.

Krajewska M, Lipiec M, Zabost A, Augustynowicz-Kopeć E, Szulowski K. 2014. Bovine tuberculosis in a wild boar (Sus scrofa) in Poland. J Wildl Dis 50:10011002

Krog JS, Hansen MS, Holm E, Hjulsager CK, Chriél M, Pedersen K, Andresen LO, Abildstrøm M, Jensen TH, Larsen LE. 2015. Influenza A (H10N7) virus in dead harbor seals, Denmark. Emerg Infect Dis 21: 684.

Kruger DH, Figueiredo LT, Song JW, Klempa B. 2015. Hantaviruses-Globally emerging pathogens. J Clin Virol 64:128-136.
Kuehn A, Schulze C, Kutzer P, Probst C, Hlinak A, Ochs A, Grunow R. 2013. Tularaemia seroprevalence of captured and wild animals in Germany: The fox (Vulpes vulpes) as a biological indicator. Epidemiol Infect 141:833-840.

Kuiken T, Ryser-Degiorgis M-P, Gavier-Widén D, Gortázar C. 2011. Establishing a European network for wildlife health surveillance. Rev Sci Tech 30:755761

Kuzmin IV, Botvinkin AD, Poleschuk EM, Orciari LA Rupprecht CE. 2006. Bat rabies surveillance in the former Soviet Union. Dev Biol (Basel) 125:273-282.

Kuzmin IV, Shi M, Orciari LA, Yager PA, Velasco-Villa A, Kuzmina NA, Streicker DG, Bergman DL, Rupprecht CE. 2012. Molecular inferences suggest multiple host shifts of rabies viruses from bats to mesocarnivores in Arizona during 2001-2009. PLoS Pathog 8:e1002786.

Laloy E, Bréard E, Sailleau C, Viarouge C, Desprat A, Zientara S, Klein F, Hars J, Rossi S. 2014 Schmallenberg virus infection among red deer, France, 2010-2012. Emerg Infect Dis 20:131-134.

Lambourn DM, Garner M, Ewalt D, Raverty S, Sidor I, Jeffries SJ, Rhyan J, Gaydos JK. 2013. Brucella pinnipedialis infections in Pacific harbor seals (Phoca vitulina richardsi) from Washington State, USA. I Wildl Dis 49:802-815.

Larska M, Krzysiak M, Smreczak M, Polak MP, Żmudziński JF. 2013. First detection of Schmallenberg virus in elk (Alces alces) indicating infection of wildlife in Białowieża National Park in Poland. Vet J 198:279-281

Lavazza A, Cavadini P, Barbieri I, Tizzani P, Pinheiro A, Abrantes J, Esteves PJ, Grilli G, Gioia E, Zanoni M. 2015. Field and experimental data indicate that the eastern cottontail (Sylvilagus floridanus) is susceptible to infection with European brown hare syndrome (EBHS) virus and not with rabbit haemorrhagic disease (RHD) virus. Vet Res 46:13.

Lavazza A, Scicluna M, Capucci L. 1996. Susceptibility of hares and rabbits to the European brown hare syndrome virus (EBHSV) and rabbit haemorrhagic disease virus (RHDV) under experimental conditions. J Vet Med B 43:401-409.

Lawson B, de Pinna E, Horton RA, Macgregor SK, John SK, Chantrey J, Duff JP, Kirkwood JK, Simpson VR, Robinson RA, et al. 2014. Epidemiological evidence that garden birds are a source of human salmonellosis in England and Wales. PLoS One 9:e88968.

Le Gall-Reculé G, Lavazza A, Marchandeau S, Bertagnoli S, Zwingelstein F, Cavadini P, Martinelli N, Lombardi G, Guérin J-L, Lemaitre E. 2013. Emergence of a new lagovirus related to rabbit haemorrhagic disease virus. Vet Res 44:81.

Le Gall-Reculé G, Lemaitre E, Gertagnoli S, Hubert C, Top S, Lequeux T, Decors A, Marchandeau S, Guitton J-S. 2016. Large scale detection of the rabbit haemorrhagic disease virus RHDV2 in European hare (Lepus europaeus) populations in France causing European brown hare syndrome EBHS-like 
outbreaks. In: Proceedings of the 5th World Lagomorph Conference, Phillips KS, Smith A, Browning C, editors. California State University, Turlock, California, 11-15 July 2016, p. 67. https://www. csustan.edu/sites/default/files/groups/ 5 th\%20World\%20Lagomorph\%20Conference/ documents/wlc5_final_program_160705.pdf. Accessed July 2018.

Le Gall-Reculé G, Zwingelstein F, Laurent S, De Boisseson C, Portejoie Y, Rasschaert D. 2003. Phylogenetic analysis of rabbit haemorrhagic disease virus in France between 1993 and 2000, and the characterisation of RHDV antigenic variants. Arch Virol 148:65-81.

Le Gall-Reculé G, Zwingelstein F, Laurent S, Portejoie Y, Rasschaert D. 2006. Molecular epidemiology of European brown hare syndrome virus in France between 1989 and 2003. Arch Virol 151:1713-1721.

Linden A, Desmecht D, Volpe R, Wirtgen M, Gregoire F, Pirson J, Paternostre J, Kleijnen D, Schirrmeier H, Beer M. 2012. Epizootic spread of Schmallenberg virus among wild cervids, Belgium, Fall 2011. Emerg Infect Dis 18:2006-2008.

Lopes AM, Capucci L, Gavier-Widen D, Le Gall-Reculé G, Brocchi E, Barbieri I, Quemener A, Le Pendu J, Geoghegan JL, Holmes EC, et al. 2014. Molecular evolution and antigenic variation of European brown hare syndrome virus (EBHSV). Virology 468-470: 104-112.

Lu L, Li C, Hagedorn CH. 2006. Phylogenetic analysis of global hepatitis E virus sequences: Genetic diversity, subtypes and zoonosis. Rev Med Virol 16:5-36.

Lycett SJ, Bodewes R, Pohlmann A, Banks J, Banyai K, Boni MF, Bouwstra R, Breed AC, Brown IH, Chen HL, et al. 2016. Role for migratory wild birds in the global spread of avian influenza H5N8. Science 354: 213-217.

Mansfield KL, Jizhou L, Phipps LP, Johnson N. 2017. Emerging tick-borne viruses in the twenty-first century. Front Cell Infect Micro 7:298.

Mari Saez A, Weiss S, Nowak K, Lapeyre V, Zimmermann F, Dux A, Kuhl HS, Kaba M, Regnaut S, Merkel K, et al. 2015. Investigating the zoonotic origin of the West African Ebola epidemic. EMBO Mol Med 7:17-23.

Márquez RA, Carvajal A, Maldonado A, Gordon S, Salas R, Gómez-Guillamón F, Sánchez-Baro A, LópezSebastián A, Santiago-Moreno J. 2014. Influence of cohabitation between domestic goat (Capra aegagrus hircus) and Iberian ibex (Capra pyrenaica hispanica) on seroprevalence of infectious diseases. Eur $J$ Wildlife Res 60:387-390.

Martel A, Blooi M, Adriaensen C, Van Rooij P, Beukema W, Fisher M, Farrer R, Schmidt B, Tobler U, Goka K. 2014. Recent introduction of a chytrid fungus endangers Western Palearctic salamanders. Science 346:630-631.

Martel A, Spitzen-van der Sluijs A, Blooi M, Bert W, Ducatelle R, Fisher MC, Woeltjes A, Bosman W, Chiers K, Bossuyt F. 2013. Batrachochytrium sala- mandrivorans sp. nov. causes lethal chytridiomycosis in amphibians. Proc Nat Acad Sci 110:15325-15329.

Martella V, Bianchi A, Bertoletti I, Pedrotti L, Gugiatti A, Catella A, Cordioli P, Lucente MS, Elia G, Buonavoglia C. 2010. Canine distemper epizootic among red foxes, Italy, 2009. Emerg Infect Dis 16:20072009.

Martin C, Pastoret P-P, Brochier B, Humblet M-F, Saegerman C. 2011. A survey of the transmission of infectious diseases/infections between wild and domestic ungulates in Europe. Vet Res 42:70.

McElhinney LM, Marston DA, Freuling CM, Cragg W, Stankov S, Lalosevic D, Lalosevic V, Muller T, Fooks AR. 2011. Molecular diversity and evolutionary history of rabies virus strains circulating in the Balkans. J Gen Virol 92:2171-2180.

McElhinney LM, Marston DA, Leech S, Freuling CM, van der Poel WH, Echevarria J, Vazquez-Moron S, Horton DL, Muller T, Fooks AR. 2013. Molecular epidemiology of bat lyssaviruses in Europe. Zoonoses Public Health 60:35-45.

McMahon TA, Sears BF, Venesky MD, Bessler SM, Brown JM, Deutsch K, Halstead NT, Lentz G, Tenouri N, Young S. 2014. Amphibians acquire resistance to live and dead fungus overcoming fungal immunosuppression. Nature 511:224-227.

Med-Vet-Net. 2008. Medical-Veterinary-Network-A Network of Excellence for Zoonoses research funded by the European Union. http://mvnassociation.org/ medvetnet/index.php/association.

Meli ML, Simmler P, Cattori V, Martínez F, Vargas A, Palomares F, López-Bao JV, Simón MA, López G, León-Vizcaino $L_{\wedge}$ 2010. Importance of canine distemper virus (CDV) infection in free-ranging Iberian lynxes (Lynx pardinus). Vet Microbiol 146:132-137.

Meredith A, Cleaveland S, Denwood M, Brown J, Shaw D. 2015. Coxiella burnetii (Q-Fever) seroprevalence in prey and predators in the United Kingdom: Evaluation of infection in wild rodents, foxes and domestic cats using a modified ELISA. Transbound Emerg Dis 62:639-649.

Mick V, Le Carrou G, Corde Y, Game Y, Jay M, GarinBastuji B. 2014. Brucella melitensis in France: Persistence in wildlife and probable spillover from Alpine ibex to domestic animals. PLoS One 9:e94168.

Millán J, Ferroglio E, Solano-Gallego L. 2014. Role of wildlife in the epidemiology of Leishmania infantum infection in Europe. Parasitol Res 113:2005-2014.

Molina R, Jiménez M, Cruz I, Iriso A, Martín-Martín I, Sevillano O, Melero S, Bernal J. 2012. The hare (Lepus granatensis) as potential sylvatic reservoir of Leishmania infantum in Spain. Vet Parasitol 190:268271.

Muller T, Freuling CM, Wysocki P, Roumiantzeff M, Freney J, Mettenleiter TC, Vos A. 2015. Terrestrial rabies control in the European Union: Historical achievements and challenges ahead. Vet J 203:10-17.

Negredo A, Palacios G, Vazquez-Moron S, Gonzalez F, Dopazo H, Molero F, Juste J, Quetglas J, Savji N, de la Cruz Martinez M, et al. 2011. Discovery of an 
ebolavirus-like filovirus in europe. PLoS Pathog 7: e1002304.

Nguyen TT, Nguyen TV, Ziegler T, Pasmans F, Martel A. 2017. Trade in wild anurans vectors the urodelan pathogen Batrachochytrium salamandrivorans into Europe. Amphibia-Reptilia 38:554-556.

Nikolay B. 2015. A review of West Nile and Usutu virus co-circulation in Europe: How much do transmission cycles overlap? Trans R Soc Trop Med Hyg 109:609618.

Nikolin VM, Wibbelt G, Michler F-UF, Wolf P, East ML. 2012. Susceptibility of carnivore hosts to strains of canine distemper virus from distinct genetic lineages. Vet Microbiol 156:45-53.

Nolden T, Banyard AC, Finke S, Fooks AR, Hanke D, Höper D, Horton DL, Mettenleiter TC, Müller T, Teifke JP, et al. 2014. Comparative studies on the genetic, antigenic and pathogenic characteristics of Bokeloh bat lyssavirus. J Gen Virol 95:1647-1653.

Norwegian Veterinary Institute (NVI). 2018. Surveillance and eradication efforts towards CWD. https://www. vetinst.no/nyheter/surveillance-and-eradicationefforts-towards-cwd. Accessed 12 March 2018.

Nymo IH, Tryland M, Frie AK, Haug T, Foster G, Rødven R, Godfroid J. 2013. Age-dependent prevalence of anti-brucella antibodies in hooded seals Cystophora cristata. Dis Aquat Org 106:187-196.

OIE (World Organization for Animal Health). 2013. The OIE worldwide monitoring system for wild animal diseases. http://www.oie.int/wahis_2/public/ wahidwild.php. Accessed June 2018.

OIE. 2017. OIE situation report for avian influenza. http://www.oie.int/fileadmin/Home/eng/Animal_ Health_in_the_World/docs/pdf/OIE_AI_situation_ report/OIE_SituationReport_AI_1_13March2017. pdf. Accessed June 2018.

OIE. 2018. OIE listed diseases, infections and infestations in force in 2018. http://www.oie.int/en/animal-healthin-the-world/oie-listed-diseases-2018/ Accessed June 2018.

Olival KJ, Hayman DT. 2014. Filoviruses in bats: Current knowledge and future directions. Viruses 6:17591788 .

Origgi F, Plattet P, Sattler U, Robert N, Casaubon J, Mavrot F, Pewsner M, Wu N, Giovannini S, Oevermann $A \wedge$ 2012. Emergence of canine distemper virus strains with modified molecular signature and enhanced neuronal tropism leading to high mortality in wild carnivores. Vet Pathol 49:913-929.

Origgi FC, Wu N, Pilo P. 2013 Francisella tularensis infection in a stone marten (Martes foina) without classic pathological lesions consistent with tularemia. J Vet Diagn Invest 25:519-521.

Otsuki N, Sekizuka T, Seki F, Sakai K, Kubota T, Nakatsu Y, Chen S, Fukuhara H, Maenaka K, Yamaguchi R. 2013. Canine distemper virus with the intact $\mathrm{C}$ protein has the potential to replicate in human epithelial cells by using human nectin 4 as a receptor. Virology 435:485-492.
Padgett KA, Reisen WK, Kahl-Purcell N, Fang Y, Cahoon-Young B, Carney R, Anderson N, Zucca L, Woods L, Husted S. 2007. West Nile virus infection in tree squirrels (Rodentia: Sciuridae) in California, 2004-2005. Amer J Trop Med Hyg 76:810-813.

Pasmans F, Van Rooij P, Blooi M, Tessa G, Bogaerts S, Sotgiu G, Garner TW, Fisher MC, Schmidt BR, Woeltjes T. 2013. Resistance to chytridiomycosis in European plethodontid salamanders of the genus Speleomantes. Plos, One 8:e63639.

Pavio N, Meng X-J, Renou C. 2010. Zoonotic hepatitis E: Animal reservoirs and emerging risks. Vet Res 41:46.

Pejsak Z, Markowska-Daniel I. 2015. Current situation on African Swine Fever (ASF). Proceedings of the 7th International Symposium on Emerging and Reemerging Pig Diseases, Kyoto, pp. 36-40 pp. Available from the the first author upon request.

Pejsak Z, Truszczyński M, Kozak E, Markowska-Daniel I. 2014. Epidemiological analysis of two first cases of African swine fever in wild boars in Poland. Med Weter 70:369-372.

Perrotey S, Mahamdallie SS, Pesson B, Richardson KJ, Gállego M, Ready PD. 2005. Postglacial dispersal of Phlebotomus perniciosus into France. Parasite 12: 283-291.

Petersen LR, Brault AC, Nasci RS. 2013. West Nile virus: Review of the literature. JAMA 310:308-315.

Piarroux M, Piarroux R, Knapp J, Bardonnet K, Dumortier J, Watelet J, Gerard A, Beytout J, Abergel A, Bresson-Hadni S. 2013. Populations at risk for alveolar echinococcosis, France. Emerg Infect Dis 19: 721-728.

Picard-Meyer E, Mrenoshki S, Milicevic V, Ilieva D, Cvetkovikj I, Cvetkovikj A, Krstevski K, Dzhadzhovski I, Robardet E, Gagnev E, et al. 2013. Molecular characterisation of rabies virus strains in the Republic of Macedonia. Arch Virol 158:237-240.

Pohlmann A, Starick E, Harder T, Grund C, Höper D, Globig A, Staubach C, Dietze K, Strebelow G, Ulrich RG. 2017. Outbreaks among wild birds and domestic poultry caused by reassorted influenza A (H5N8) clade 2.3. 4.4 viruses, Germany, 2016. Emerg Infect Dis 23:633.

Pounder KC, Begon M, Sironen T, Henttonen H, Watts PC, Voutilainen L, Vapalahti O, Klempa B, Fooks AR, McElhinney LM. 2013. Novel hantavirus in field vole, United Kingdom. Emerg Infect Dis 19:673-675.

Price SJ, Garner TW, Nichols RA, Balloux F, Ayres C, de Alba AM-C, Bosch J. 2014. Collapse of amphibian communities due to an introduced Ranavirus. Curr Biol 24:2586-2591.

Prodinger WM, Indra A, Koksalan OK, Kilicaslan Z, Richter E. 2014. Mycobacterium caprae infection in humans. Expert Rev Anti Infect Ther 12:1501-1513.

ProMED-Mail. 2016. Crimean Congo hemorrhagic fever-Spain (03): ECDC risk assessment. http://www. promedmail.org/post/20160912.4481430CrimeanCongo. Accessed June 2018.

Puechmaille SJ, Wibbelt G, Korn V, Fuller H, Forget F, Mühldorfer K, Kurth A, Bogdanowicz W, Borel C, 
Bosch T. 2011. Pan-European distribution of whitenose syndrome fungus (Geomyces destructans) not associated with mass mortality. Plos One 6:e19167.

Puggioni G, Cavadini P, Maestrale C, Scivoli R, Botti G, Ligios C, Le Gall-Reculé G, Lavazza A, Capucci L. 2013. The new French 2010 rabbit hemorrhagic disease virus causes an RHD-like disease in the Sardinian Cape hare (Lepus capensis mediterraneus). Vet Res 44:96.

Racey PA, Hutson AM, Lina PH. 2013. Bat rabies, public health and European bat conservation. Zoonoses Public Health 60:58-68.

Ravagnan S, Montarsi F, Cazzin S, Porcellato E, Russo F, Palei M, Monne I, Savini G, Marangon S, Barzon L. 2015. First report outside Eastern Europe of West Nile virus lineage 2 related to the Volgograd 2007 strain, northeastern Italy, 2014. Parasit Vectors 8:418.

Reid S, Shell W, Barboi G, Onita I, Turcitu M, Cioranu R, Marinova-Petkova A, Goujgoulova G, Webby R, Webster R, et al. 2010. First reported incursion of highly pathogenic notifiable avian influenza A $\mathrm{H} 5 \mathrm{~N} 1$ viruses from clade 2.3.2 into European poultry. Transbound Emerg Dis 58:76-78.

Rentería-Solís Z, Förster C, Aue A, Wittstatt U, Wibbelt G, König M. 2014. Canine distemper outbreak in raccoons suggests pathogen interspecies transmission amongst alien and native carnivores in urban areas from Germany. Vet Microbiol 174:50-59.

Rijks JM, Kik M, Koene MG, Engelsma MY, van Tulden P, Montizaan MG, Oomen T, Spierenburg MA, Ijzer J, van der Giessen JW, et al. 2013. Tularaemia in a brown hare (Lepus europaeus) in 2013: First case in the Netherlands in 60 years. Euro Surveill 18:20655.

Rijks JM, Osterhaus ADME, Kuiken T. 2012. Morbillivirus infections in aquatic mammals. In: Infectious diseases of wild mammals and birds in Europe, Gavier-Widen D, Duff JPMeredith A, editors. WileyBlackwell, Oxford, UK, pp. 105-114

Roda Gracia J, Schumann B, Seidler A. 2015. Climate variability and the occurrence of human Puumala hantavirus infections in Europe: A systematic review. Zoonoses Public Health 62:465-478.

Rodriguez E, Sanchez LP, Perez S, Herrera L, Jimenez MS, Samper S, Iglesias MJ. 2009. Human tuberculosis due to Mycobacterium bovis and M. caprae in Spain, 2004-2007. Int J Tuberc Lung Dis 13:15361541.

Rodríguez S, Bezos J, Romero B, de Juan L, Álvarez J, Castellanos E, Moya N, Lozano F, Javed MT, SáezLlorente JL, et al. 2011. Mycobacterium caprae infection in livestock and wildlife, Spain. Emerg Infect Dis 17:532-535.

Roest H, Tilburg J, Van der Hoek W, Vellema P, Van Zijderveld F, Klaassen C, Raoult D. 2011. The Q fever epidemic in The Netherlands: History, onset, response and reflection. Epidemiol Infect 139:1-12.

Rónai Z, Kreizinger Z, Dán Á, Drees K, Foster JT, Bányai K, Marton S, Szeredi L, Jánosi S, Gyuranecz M. 2015. First isolation and characterization of Brucella micro$t i$ from wild boar. BMC Vet Res 11:147.
Rossi S, Pioz M, Beard E, Durand B, Gibert P, Gauthier D, Klein F, Maillard D, Saint-Andrieux C, Saubusse T. 2014. Bluetongue dynamics in French wildlife: Exploring the driving forces. Transbound Emerg Dis 61:e12-e24.

Rossi S, Viarouge C, Faure E, Gilot-Fromont E, Gache K, Gibert P, Verheyden H, Hars J, Klein F, Maillard D. 2015. Exposure of wildlife to the Schmallenberg virus in France (2011-2014): Higher, faster, stronger (than bluetongue)! Transbound Emerg Dis 64:354-363.

Rubio-Guerri C, Melero M, Esperon F, Belliere EN, Arbelo M, Crespo JL, Sierra E, Garcia-Parraga D, Sanchez-Vizcaino JM. 2013. Unusual striped dolphin mass mortality episode related to cetacean morbillivirus in the Spanish Mediterranean Sea. BMC Vet Res 9:106

Rudolf I, Betasova L, Blazejova H, Venclikova K, Strakova $\mathrm{P}$, Sebesta $\mathrm{O}$, Mendel J, Bakonyi T, Schaffner F, Nowotny N, et al. 2017. West Nile virus in overwintering mosquitoes, central Europe. Parasit Vectors 10:452.

Ruiz-Fons F, Ferroglio E, Gortázar C. 2013. Leishmania infantum in free-ranging hares, Spain, 2004-2010. Euro Surveill 18:20541.

Ruiz-Fons F, Reyes-García ÁR, Alcaide V, Gortázar C. 2008. Spatial and temporal evolution of bluetongue virus in wild ruminants, Spain. Emerg Infect Dis 14: 951-953.

Ruiz-Fons F, Sánchez-Matamoros A, Gortázar C, Sánchez-Vizcaíno JM. 2014. The role of wildlife in bluetongue virus maintenance in Europe: Lessons learned after the natural infection in Spain. Virus Res 182:50-58.

Ryden P, Sjostedt A, Johansson A. 2009. Effects of climate change on tularaemia disease activity in Sweden. Glob Health Action 2:91-97.

Ryser-Degiorgis MP. 2013. Wildlife health investigations: Needs, challenges and recommendations. BMC Vet Res 9:223.

Sánchez-Vizcaíno JM, Mur L, Martínez-López B. 2013. African swine fever (ASF): Five years around Europe. Vet Microbiol 165:45-50.

Schatz J, Fooks AR, McElhinney L, Horton D, Echevarria J, Vazquez-Moron S, Kooi EA, Rasmussen TB, Muller T, Freuling CM. 2013. Bat rabies surveillance in Europe. Zoonoses Public Health 60:22-34.

Schmeller DS, Blooi M, Martel A, Garner TW, Fisher MC, Azemar F, Clare FC, Leclerc C, Jäger L, Guevara-Nieto M. 2014. Microscopic aquatic predators strongly affect infection dynamics of a globally emerged pathogen. Curr Biol 24:176-180.

Scholz HC, Hofer E, Vergnaud G, Fleche PL, Whatmore AM, Dahouk SA, Pfeffer M, Krüger M, Cloeckaert A, Tomaso H. 2009. Isolation of Brucella microti from mandibular lymph nodes of red foxes, Vulpes vulpes, in lower Austria. Vector Borne Zoonotic Dis 9:153156.

Scholz HC, Hubalek Z, Sedláček I, Vergnaud G, Tomaso H, Al Dahouk S, Melzer F, Kämpfer P, Neubauer H, Cloeckaert A. 2008. Brucella microti sp. nov., isolated 
from the common vole Microtus arvalis. Int J Syst Evol Microbiol 58:375-382.

Scholz HC, Revilla-Fernández S, Al Dahouk S, Hammerl JA, Zygmunt MS, Cloeckaert A, Koylass M, Whatmore AM, Blom J, Vergnaud G. 2016. Brucella vulpis sp. nov., isolated from mandibular lymph nodes of red foxes (Vulpes vulpes). Int J Syst Evol Microbiol 66:2090-2098

Semenza JC, Menne B. 2009. Climate change and infectious diseases in Europe. Lancet Infect Dis 9: 365-375.

Semenza JC, Rocklov J, Penttinen P, Lindgren E. 2016. Observed and projected drivers of emerging infectious diseases in Europe. Ann NY Acad Sci 1382:7383.

Simons RR, Gale P, Horigan V, Snary EL, Breed AC. 2014. Potential for introduction of bat-borne zoonotic viruses into the EU: A review. Viruses 6:2084-2121.

Skerratt LF, Berger L, Speare R, Cashins S, McDonald KR, Phillott AD, Hines HB, Kenyon N. 2007. Spread of chytridiomycosis has caused the rapid global decline and extinction of frogs. EcoHealth 4:125-134.

Sohn H-J, Kim J-H, Choi K-S, Nah J-J, Joo Y-S, Jean Y-H, Ahn S-W, Kim O-K, Kim D-Y, Balachandran A. 2002. A case of chronic wasting disease in an elk imported to Korea from Canada. J Vet Med Sci 64:855-858.

Spengler JR, Bergeron É, Rollin PE. 2016. Seroepidemiological studies of Crimean-Congo hemorrhagic fever virus in domestic and wild animals. PLoS Negl Trop Dis 10:e004210.

Spitzen-van der Sluijs A, Martel A, Hallmann CA, Bosman W, Garner TW, Van Rooij P, Jooris R, Haesebrouck F, Pasmans F. 2014. Environmental determinants of recent endemism of Batrachochytrium dendrobatidis infections in amphibian assemblages in the absence of disease outbreaks. Conserv Biol 28:1302-1311.

Stegen G, Pasmans F, Schmidt BR, Rouffaer LO, Van Praet S, Schaub M, Canessa S, Laudelout A, Kinet T, Adriaensen C, et al. 2017. Drivers of salamander extirpation mediated by Batrachochytrium salamandrivorans. Nature 544:353-356.

Szentpali-Gavaller K, Antal L, Toth M, Kemenesi G, Soltesz Z, Dan A, Erdelyi K, Banyai K, Baalint A, Jakab F, et al. 2014. Monitoring of West Nile virus in mosquitoes between 2011-2012 in Hungary. VectorBorne Zoonotic Dis 14:648-655.

Szulowski K, Iwaniak W, Weiner M, Zlotnicka J. 2013. Brucella suis biovar 2 isolations from cattle in Poland. Ann Agric Environ Med 20:462-465.

Tavernier P, Baert K, van de Bildt M, Kuiken T, Cay AB, Maes S, Roels S, Gouwy J, van den Berge K. 2012. A distemper outbreak in beech martens (Martes foina) in Flanders. Vlaams Diergen Tijds 81:81-87.

Teacher A, Cunningham A, Garner T. 2010. Assessing the long-term impact of ranavirus infection in wild common frog populations. Anim Conserv 13:514522 .

Thomas K, Tompkins DM, Sainsbury AW, Wood AR, Dalziel R, Nettleton PF, McInnes CJ. 2003. A novel poxvirus lethal to red squirrels (Sciurus vulgaris). J Gen Virol 84:3337-3341.

Thomas S. 2012. Canine distemper outbreak in ferrets in the UK. Vet Rec 170:27.

Timm R, Cuarón A, Reid F, Helgen K, Gonzalez-Maya JF. 2016. Procyon lotor: IUCN Red List of Threatened Species. http://dx.doi.org/10.2305/IUCN.UK.2016-1. RLTS.T41686A45216638.en. Accessed July 2018.

Trebbien R, Chriel M, Struve T, Hjulsager CK, Larsen G, Larsen LE. 2014. Wildlife reservoirs of canine distemper virus resulted in a major outbreak in Danish farmed mink (Neovison vison). Plos One 9: e85598.

Tsiodras S, Dougas G, Baka A, Billinis C, Doudounakis S, Balaska A, Georgakopoulou T, Rigakos G, Kontos V, Tasioudi KE, et al. 2013. Re-emergence of animal rabies in northern Greece and subsequent human exposure, October 2012 -March 2013. Euro Surveill 18:20474

Umhang G, Comte S, Raton V, Hormaz V, Boucher J-M, Favier S, Combes B, Boué F. 2014. Echinococcus multilocularis infections in dogs from urban and periurban areas in France. Parasitol Res 113:2219-2222.

Vaheri A, Henttonen H, Voutilainen L, Mustonen J, Sironen T, Vapalahti O. 2013. Hantavirus infections in Europe and their impact on public health. Rev Med Virol 23:35-49.

van den Brand JMA, Haagmans BL, van Riel D, Osterhaus ADME, Kuiken T. 2014. The pathology and pathogenesis of experimental severe acute respiratory syndrome and influenza in animal models. J Comp Path 151:83-112.

van den Brand JMA, Wohlsein P, Herfst S, Bodewes R, Pfankuche VM, van de Bildt MWG, Seehusen F, Puff C, Richard M, Siebert U, et al. 2016. Influenza A (H10N7) virus causes respiratory tract disease in harbor seals and ferrets. PLoS One 11:e0159625.

Van Der Goot J, Verhagen J, Gonzales J, Backer J, Bongers J, Boender GJ, Fouchier R, Koch G. 2013. [Low pathogenic avian influenza virus infection at fowl farms in the Netherlands]. Tijdschr Diergeneeskd 138:24-27, 29.

van Elk CE, van de Bildt MW, Jauniaux T, Hiemstra S, van Run PR, Foster G, Meerbeek J, Osterhaus AD, Kuiken T. 2014. Is dolphin morbillivirus virulent for white-beaked dolphins (Lagenorhynchus albirostris)? Vet Pathol 51:1174-1182.

Velarde R, Cavadini P, Neimanis A, Cabezón O, Chiari M, Gaffuri A, Lavín S, Grilli G, Gavier-Widén D, Lavazza A. 2016. Spillover events of infection of brown hares (Lepus europaeus) with rabbit haemorrhagic disease type 2 virus (RHDV2) caused sporadic cases of a European brown hare syndrome-like disease in Italy and Spain. Transbound Emerg Dis 64:1750-1761

Verhagen JH, van der Jeugd HP, Nolet BA, Slaterus R, Kharitonov SP, de Vries PP, Vuong O, Majoor F, Kuiken T, Fouchier RA. 2015. Wild bird surveillance around outbreaks of highly pathogenic avian influenza A(H5N8) virus in the Netherlands, 2014, within 
the context of global flyways. Euro Surveill 20:pii: 21069.

Verner-Carlsson J, Lohmus M, Sundstrom K, Strand TM, Verkerk M, Reusken C, Yoshimatsu K, Arikawa J, van de Goot F, Lundkvist A. 2015. First evidence of Seoul hantavirus in the wild rat population in the Netherlands. Infect Ecol Epidemiol 5:27215.

Viana M, Cleaveland S, Matthiopoulos J, Halliday J, Packer C, Craft ME, Hampson K, Czupryna A, Dobson AP, Dubovi Eh 2015. Dynamics of a morbillivirus at the domestic-wildlife interface: Canine distemper virus in domestic dogs and lions. Proc Nat Acad Sci 112:1464-1469.

VKM (Vitenskapskomiteen for mattrygghet [Norwegian Scientific Committee for Food Safety]). 2016. CWD in Norway. Opinion of the panel on biological hazards. VKM, Oslo, Norway, $75 \mathrm{pp}$, https://vkm. no/download/18.2994e95b15cc54507161c8d6/ $1498205580043 / \mathrm{CWD} \% 20$ in\%20Norway.pdf. Accessed June 2018

VKM. 2017. CWD in Norway-A state of emergency for the future of cervids (Phase II). Opinion of the panel on biological hazards. VKM Report 2017:9, Oslo, Norway, 125 pp. https://vkm.no/download/18. 645b840415d03a2fe8f253c5/1509532944615 CWD \%20in \%20 Norway\%20-\%20a\%20 state $\% 20$ of $\% 20$ emergency $\% 20$ for $\% 20$ the $\% 20$ future $\% 20$ of\%20cervids\%20(Phase\%20II).pdf. Accessed June 2018.

Vonesch N, D'Ovidio MC, Melis P, Remoli ME, Ciufolini MG, Tomao P. 2016. Climate change, vector-borne diseases and working population. Ann Istituto Super Sanita 52:397-405.

Vos A, Ortmann S, Kretzschmar AS, Kohnemann B, Michler F. 2012. The raccoon (Procyon lotor) as potential rabies reservoir species in Germany: A risk assessment. Berl Munch Tierarztl Wochenschr 125: 228-235.

Wahlström H, Lindberg A, Lindh J, Wallensten A, Lindqvist R, Plym-Forshell L, Lind EO, Ågren E, Widgren S, Carlsson $\mathrm{U}_{\overline{\mathbf{z}}}$ et al. 2012. Investigations and actions taken during 2011 due to the first finding of Echinococcus multilocularis in Sweden. Euro Surveill 17:pii:20215.
Wernike K, Elbers A, Beer M. 2015. Schmallenberg virus infection. Rev Sci Tech Oie 34:363-373.

Whitehouse CA. 2004. Crimean-Congo hemorrhagic fever. Antiviral Res 64:145-160.

WHO (World Health Organization). 2015. Rabies Bulletin Europe: Rabies Information System of the WHO Collaboration Centre for Rabies Surveillance and Research. http://www.who-rabies-bulletin.org. Accessed February 2015.

Wiener DJ, Welle MM, Origgi FC. 2013. Cutaneous lesions associated with dual infection caused by canine distemper virus and orthopoxvirus in a domestic cat. Vet Dermatol 24:543-e130.

Wise EL, Marston DA, Banyard AC, Goharriz H, Selden D, Maclaren N, Goddard T, Johnson N, McElhinney LM, Brouwer A, et al. 2017. Passive surveillance of United Kingdom bats for lyssaviruses (2005-2015). Epidemiol Infect 145:2445-2457.

Wolf T, Kann G, Becker S, Stephan C, Brodt HR, de Leuw P, Grunewald T, Vogl T, Kempf VA, Keppler OT, et al. 2014. Severe Ebola virus disease with vascular leakage and multiorgan failure: Treatment of a patient in intensive care. Lancet 385:1428-1435.

Woolhouse MEJ. 2002. Population biology of emerging and re-emerging pathogens. Trends Microbiol 10 (10 Suppl):3-7.

Zanet S, Sposimo P, Trisciuoglio A, Giannini F, Strumia F, Ferroglio E. 2014. Epidemiology of Leishmania infantum, Toxoplasma gondii, and Neospora caninum in Rattus rattus in absence of domestic reservoir and definitive hosts. Vet Parasitol 199:247-249.

Zieger U, Marston DA, Sharma R, Chikweto A, Tiwari K, Sayyid M, Louison B, Goharriz H, Voller K, Breed $\mathrm{AC}$, et al. 2014. The phylogeography of rabies in Grenada, West Indies, and implications for control. PLoS Negl Trop Dis 8:e3251.

Zohari S, Neimanis A, Harkonen T, Moraeus C, Valarcher J-F. 2014. Avian influenza A (H10N7) virus involvement in mass mortality of harbour seals (Phoca vitulina) in Sweden, March through October 2014. Euro Surveill 19:20967.

Submitted for publication 19 July 2017.

Accepted 5 June 2018. 
1. Author: This article has been lightly edited for grammar, style, and usage. Please compare it with your original document and make corrections on these pages. Please limit your corrections to substantive changes that affect meaning. If no change is required in response to a question, please write "OK as set" in the margin. Copy editor

2. Author: Please approve or revise the short title we have added. Copy editor

3. Author: In sentence beginning, "A surveillance program for bTB in free-ranging wildlife...," please verify that we have inserted the correct homepage URL for Sylvatub. Copy editor

4. Author: In sentence beginning, "About 29,000 animals of four species...," please verify that we have added the correct expanded name for NVI. Copy editor

5. Author: The sentence beginning, "There are no reports of fetal malformations or reproductive losses...," was slightly revised for reader clarity; does it convey your intended meaning? Copy editor

6. Author: In sentence beginning, "Recently, a novel chytrid fungus...," please verify if 'extirpation' is the correct word (i.e., extirpated from where?) or if 'extinction' is the intended meaning. Copy editor

7. Author: In the sentence beginning, "The first five agents are arthropod vector-borne," is a word missing in the phrase, "while F. tularensis may be vector-borne"? Perhaps "multihost" before "vector-borne"? Also, do you want to include a related comment about $E$. multilocularis vectors? Copy editor.

8. Author: In the Literature Cited, the ADNS 2017 information was revised to two separate references, 2017a and 2017b. Please include a distinct title for each species and provide the URL to the specific PDF so readers can find the information. Copy editor.

9. Author: In the Literature Cited, we have inserted an entry for the Table 1 footnote d, "Med-Vet-Net 2008," which requires a full reference. Please verify if we have inserted the correct url. Copy editor

10. Author: In the Table 2 caption, please explain the dashes we have inserted in all blank cells, per journal style (e.g., no data or not applicable?). Copy editor, 